\title{
FAMILY DYNAMICS AND HEALTH ATTITUDES
}

\author{
by
}

RACHEL YVONNE WITHAM

B.S., Kansas State University, 2009

\begin{abstract}
A THESIS
submitted in partial fulfillment of the requirements for the degree

\section{MASTER OF SCIENCE}

Department of Special Education, Counseling, and Student Affairs College of Education

\section{KANSAS STATE UNIVERSITY \\ Manhattan, Kansas}

2011

Approved by:

Major Professor

Brandonn S. Harris 


\begin{abstract}
The present study examined adolescents' perceptions of their caregivers' parenting style as well as their physical activity participation, motivation, and attitudes. High school students completed questionnaires regarding their physical activity participation, motivation, and attitudes, and they assessed both their male and female caregivers' parenting style. Results indicated that for males, a permissive parenting style was related to more physical activity participation and that males favor physical activity that features long and hard training and as a way to stay healthy and fit. An authoritative parenting style was related to higher rates of physical activity for females, and their attitudes focused on social aspects of physical activity as well as a release of tension. For both genders, identified regulation was associated with higher rates of physical activity, indicating that higher levels of self-determined motivation are important for promoting active behaviors. Cross-gender relationships between caregiver and child emerged and social and gender norms seemed to influence parenting style and attitudes specific to gender. Additional results and implications are discussed.
\end{abstract}




\section{Table of Contents}

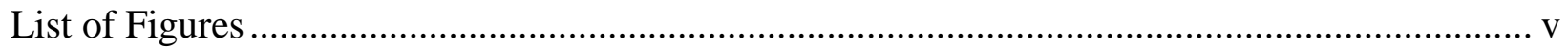

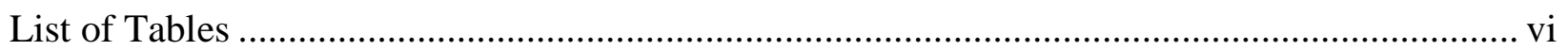

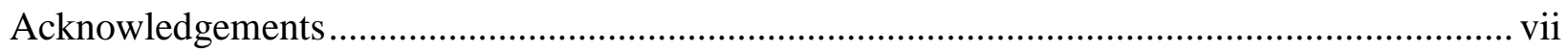

Chapter 1 - Introduction and Statement of the Problem ...................................................... 1

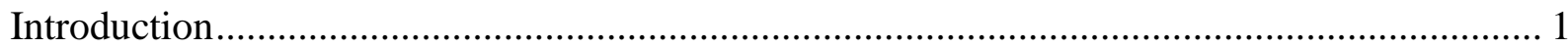

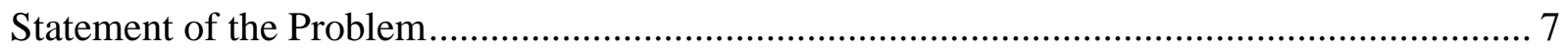

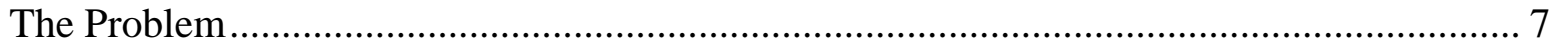

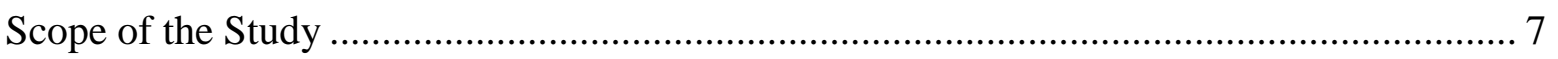

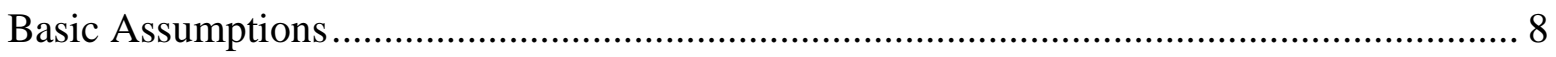

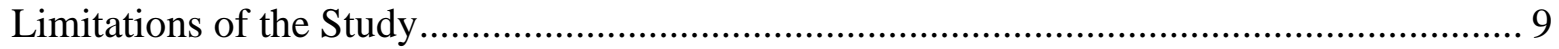

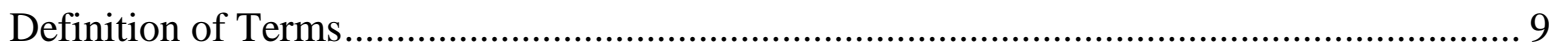

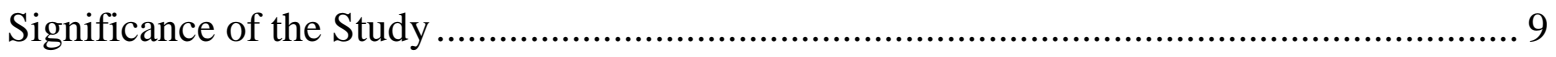

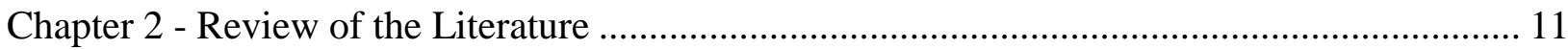

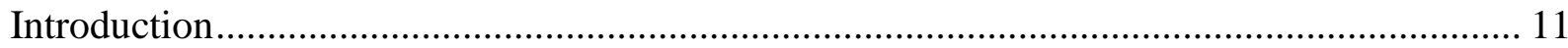

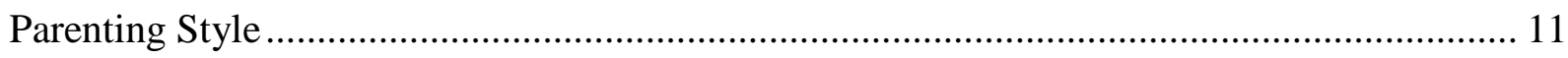

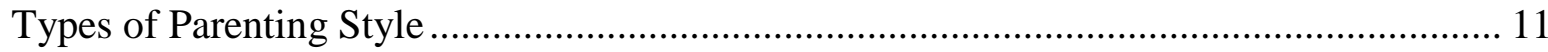

Parenting Style and its Relationship to Aspects of Development................................... 13

Parental Effects on Child and Adolescent Physical Activity Behaviors .............................. 15

Physical Activity Motivation and Attitudes................................................................... 18

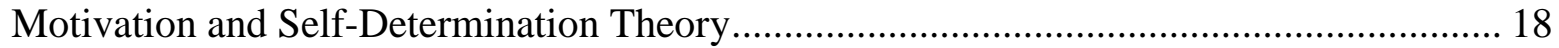

Attitudes toward Physical Activity ....................................................................... 20

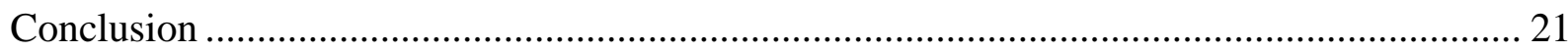

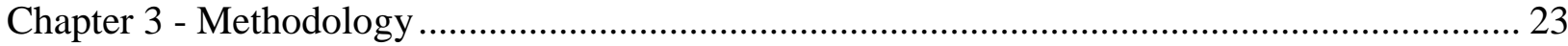

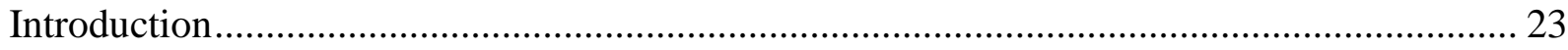

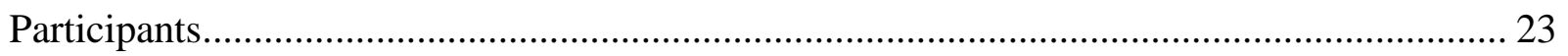

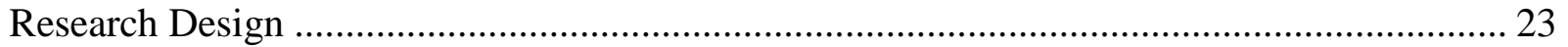

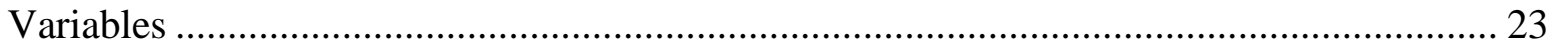

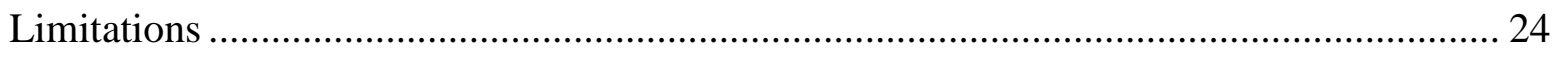

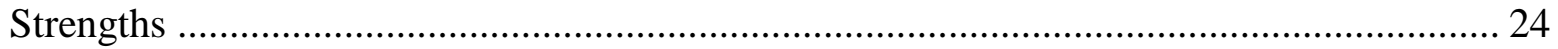




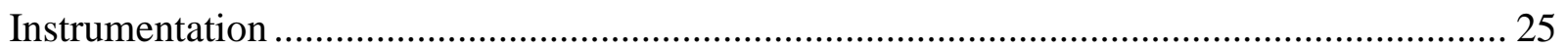

Parental Authority Questionnaire (PAQ) ……………………………………………....... 25

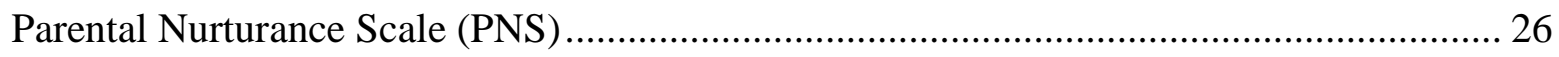

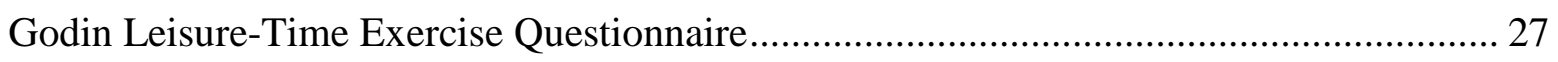

Children's Attitudes toward Physical Activity (CATPA) .................................................... 28

Behavioral Regulation in Exercise Questionaire-2 (BREQ-2) ............................................. 29

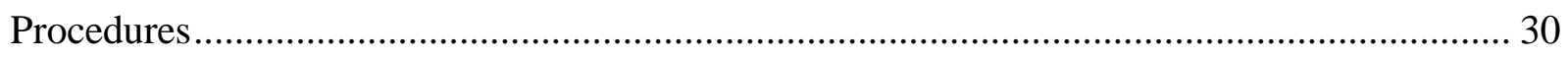

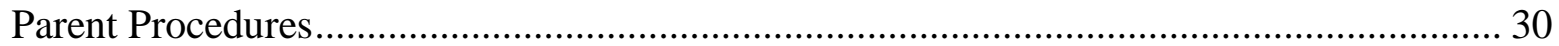

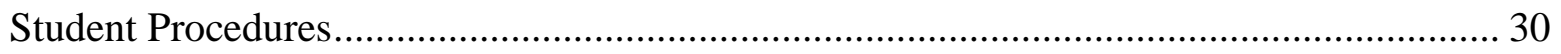

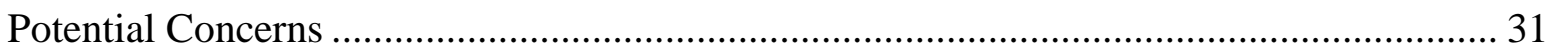

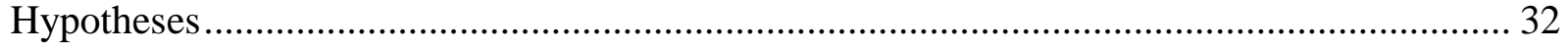

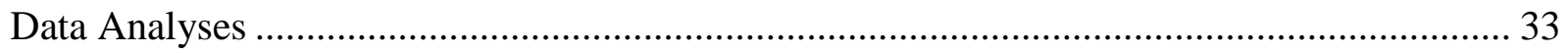

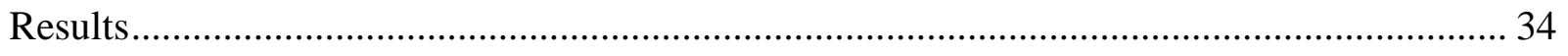

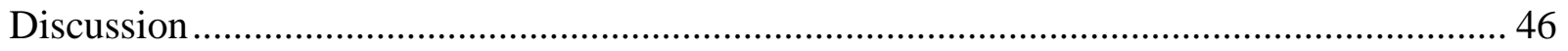

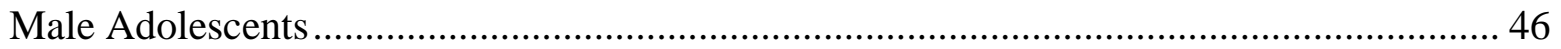

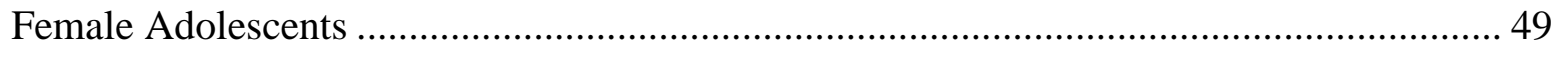

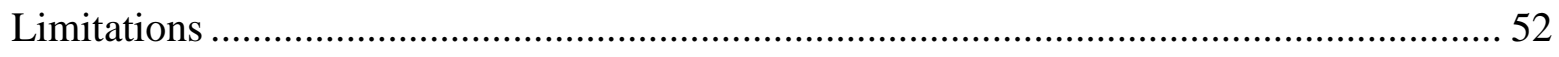

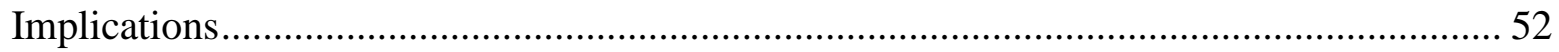

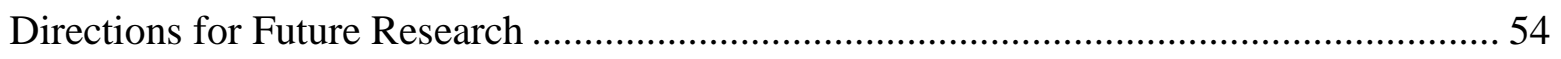

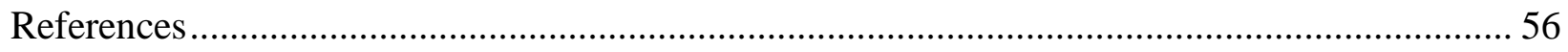

Appendix A - Parental Authority Questionnaire (PAQ) and Parental Nurturance Scale (PNS)

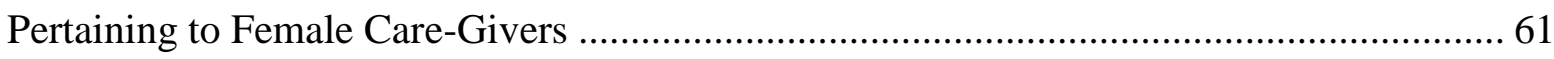

Appendix B - Parental Authority Questionnaire (PAQ) and Parental Nurturance Scale (PNS)

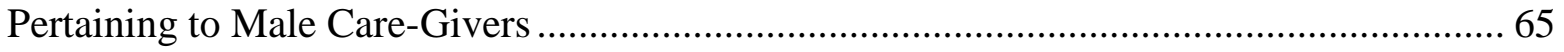

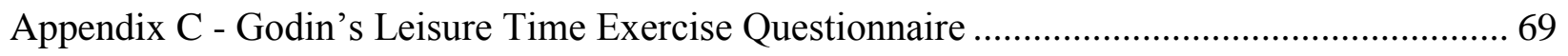

Appendix D - Children's Attitudes Toward Physical Activity (CATPA) Inventory ..................... 71

Appendix E - Behavioral Regulation in Exercise Questionnaire-2 (BREQ-2)............................. 74

Appendix F - Informed Consent ........................................................................................... 76 


\section{List of Figures}

Figure 2.1 Self-Determination Theory Continuum of Motivation......................................... 19 


\section{List of Tables}

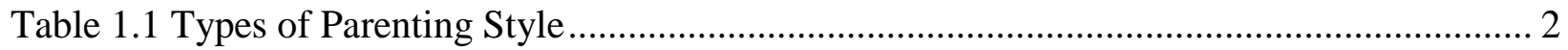

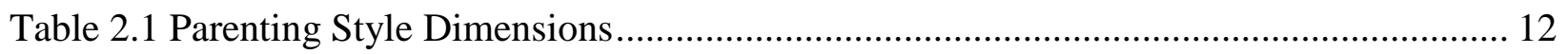

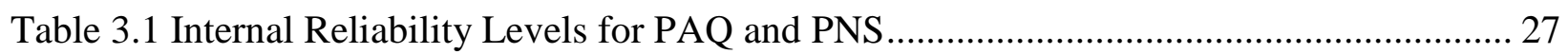

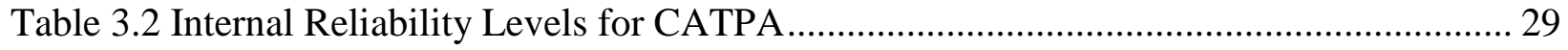

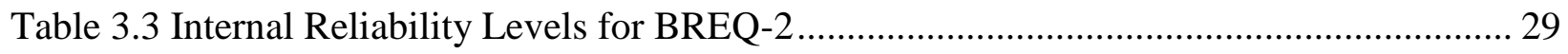

Table 3.4 Correlations for Male Caregiver's Parenting Style and Physical Activity ................. 35

Table 3.5 Correlations for Female Caregiver's Parenting Style and Physical Activity............... 35

Table 3.6 Correlations for Male Caregiver's Parenting Style and Adolescent Motivation .......... 36

Table 3.7 Correlations for Female Caregiver's Parenting Style and Adolescent Motivation ...... 37

Table 3.8 Correlations for Male Caregiver's Parenting Style and Adolescent Attitudes ............ 38

Table 3.9 Correlations for Female Caregiver's Parenting Style and Adolescent Attitudes......... 38

Table 3.10 Correlations for Adolescent Attitudes and Physical Activity Participation .............. 40

Table 3.11 Correlations for Adolescent Motivation and Physical Activity Participation ........... 40

Table 3.12 Means and Standard Deviation for All Research Variables .................................... 42 


\section{Acknowledgements}

Special thanks to the school districts of Riley County (USD 383), Junction City (USD

475), and Jefferson West (USD 340) and the administration and teachers who allowed this study to take place within their high school. 


\section{Chapter 1 - Introduction and Statement of the Problem}

\section{Introduction}

For over half a century, the interactions between parents and their children have been extensively researched to determine the impact that different parenting practices have on the development of children. Within this line of research, the concept of parenting style has been defined as an entire collection of attitudes that are communicated from parent to child that creates an emotional climate in which the parent's behaviors are expressed (Darling \& Steinberg, 1993). A leading researcher in the area of parenting style, Diana Baumrind, has identified two general dimensions of parenting that comprise four distinct parenting styles (Baumrind, 1971; 1991; Berge, Wall, Loth, \& Neumark-Sztainer, 2010; Cole, Cole, \& Lightfoot, 2005). One general dimension is referred to as demandingness and involves the discipline and expectations a parent has for their child and how they enforce these demands to their child. The other dimension of responsiveness refers to the level of support and individuality that a parent fosters for their children (Baumrind, 1991). Parenting style can be measured on each of these dimensions which yields either a high or a low score to create four orthogonal groups (e.g., high demandingness and high responsiveness, high demandingness and low responsiveness, low demandingness and high responsiveness, and low demandingness and low responsiveness). Each one of these groups can be identified as one of four parenting styles: authoritative, authoritarian, permissive, and rejecting-neglecting or disengaged.

Baumrind $(1971 ; 1991)$ provided definitions for each of the four distinct parenting styles (see Table 1.1). Authoritative parents typically score high on both the demandingness and the responsiveness dimensions of parenting behaviors. While they are demanding, they also value the rights of their children and use reasoning over physical punishment. Authoritative parents 
also set high standards for their children's behavior and encourage independence in a supporting environment. Contrastingly, authoritarian parents have been found to be high on the demandingness dimension but low on the responsiveness dimension. They value obedience and order, and they provide a clear set of rules and monitor their children's behavior closely. While authoritative parents use reasoning and are free to talk openly with their children, authoritarian parents are more likely to use punitive measures and not encourage verbal exchange between themselves and their children. Permissive parents are low on the demandingness dimension but high in the responsiveness dimension. While they foster self-regulation and a considerable amount of independence within their children, they lack rules or expectations and they avoid confrontation with their children. Finally, rejecting-neglecting (sometimes referred to as disengaged) parents are low on both dimensions of parenting style. This parenting style is typically characterized by failing to provide structure or support for their children in either an actively rejecting or neglecting pattern of behavior.

\section{Table 1.1 Types of Parenting Style}

\section{$\underline{\text { Parenting Style }}$}

Authoritative

Authoritarian

Permissive

Rejecting-Neglecting

\begin{tabular}{cc}
\multicolumn{2}{c}{ Dimension } \\
Demandingness & Responsiveness \\
\cline { 2 - 2 } High & High \\
High & Low \\
Low & High \\
Low & Low
\end{tabular}

The question of many researchers and parents often regards which, if any, parenting style is considered the most effective for raising children. The majority of research conducted on parenting style and development in children has identified authoritative parents as those who generate competent children (Baumrind, 1991). Authoritative parents, or those who have high 
demands but also provide a high amount of responsiveness, have also been successful in fostering high self-esteem (Buri, 1989) and lowering problem drug use among their children (Baumrind, 1991; Newman, Harrison, Dashiff, \& Davies, 2008). Additional risk factors for adolescents such as depression, suicide, violence, unhealthy sexual behaviors, and unhealthy eating were also less likely to be found in adolescents who lived with at least one authoritative parent (Newman et al., 2008). While family dynamics and cultural variables are different within each family, the majority of research highlights the benefits of balancing high demands with high responsiveness, as is the case for authoritative parents. It seems that an authoritative parenting style has been shown to foster more protective factors in children and lead to a lower incidence of problem behaviors in adolescents.

In addition to examining the effectiveness or impact of various parenting styles on children's behavior, research has also revealed some cultural differences regarding the effect of parenting style on the development of children across several aspects of their lives. While authoritativeness is seen as the most beneficial parenting style for fostering high academic achievement and psycho-social adjustment in European-American children, it is not effective in influencing the academic achievement of Asian- and African-American adolescents (Darling \& Steinberg, 1993). Additionally, while authoritarian parents who are high in demands but provide a minimal amount of support are associated with a fearful compliance in European Americans, this parenting style is associated with assertiveness among African American girls (Darling \& Steinberg). In light of these cultural differences, Darling and Steinberg propose that parenting style be viewed within the context of the family, including cultural variables. Future research should continue to utilize diverse samples to gain more answers to cultural differences within families and parenting style. 
An additional area of research regarding the development of children is the influence parents may have on children's health behaviors. Parenting style factors can be contributing in the decline of physical activity participation in children and the increase of over-weight and obese children. Many of the same qualities that are fostered in children through an authoritative parenting style (e.g. responsibility, self-regulation, individuality) are also associated with positive attitudes toward sport and physical activity participation and motivation (Brustad \& Partridge, 2002). Research has emphasized the importance of providing parental support to adolescents to foster physical activity participation (Gustufson \& Rhodes, 2006; Pugliese \& Tinsley, 2007; Van Der Horst, Paw, Twisk, \& Van Mechelen, 2007). It is evident from this body of research that parental support and involvement is critical for fostering physical activity participation in youth, however formal measures of parenting style are needed to specify what level of parental support is the most beneficial in fostering these healthy behaviors.

While parental support has been found to be associated with higher physical activity participation in children and adolescents, the body of research specifically examining parenting styles with physical activity behaviors is limited. The levels of support, responsiveness, and demandingness as suggested by Baumrind's $(1971 ; 1991)$ parenting styles provide the specificity needed to further examine the relationship between parenting style and physical activity participation among children and adolescents. To date however, there is a paucity of research examining these variables. While researching the effects of parenting style on various risk factors among adolescents, Newman, Harriston, Dashiff, and Davies (2008) found that no studies examining relationships between parenting styles and physical activity existed in the literature. More recently, Berge, Wall, Loth, and Neumark-Sztainer (2010) examined parenting style and adolescent physical activity participation, along with other health-related factors such as body 
mass index (BMI) and dietary intake. Their findings suggested that the benefits of an authoritative parenting style may include a reduction in the incidence of unhealthy eating and being overweight; however, significant associations were not found between parenting style and adolescent physical activity (Berge et al., 2010). The present study will continue this line of research by examining the relationship between parenting style and adolescent physical activity participation, and will extend this area of research by adding an examination of psychosocial factors related to physical activity participation.

Additional factors that are highly related and influential on physical activity participation such as motivation to be physically active and attitudes toward physical activity have also not been examined in regards to parenting style. The self-determination theory (Deci \& Ryan, 1985) has been a widely utilized theory in the study of motivation and has recently been used as a theoretical approach to examining adolescent physical activity (Chatzisarantis, Biddle, \& Meek, 1997; Gillison, Standage, \& Skevington, 2006; Markland \& Tobin, 2004). Self-determination theory (SDT) accounts for the psychological needs and motives of the individual's behavior of interest and focuses on aligning motives for behavior with the individual's need for autonomy (Chatzisarantis et al., 1997). SDT proposes that self-determined motivation or more intrinsic factors leads to positive behavioral outcomes, while behavior low in self-determination or more extrinsic motivational factors leads to a loss of interest or drop-out form a particular activity (Gillison et al., 2006). When measuring motivation from a SDT approach, motivation is placed on a continuum from amotivation, through extrinsic motivation, to intrinsic motivation (Gillison et al., 2006). Examining motivation using SDT as a framework can aide in our understanding of adolescents' reasons for participation in physical activity, or lack thereof. For example, Gillison et al. (2006) found that intrinsic goals positively predicted self-determined motivation in 
adolescents which in turn positively predicted exercise behavior. By examining the association between parenting style and motivation to engage in physical activity, we can better understand what level of parental demandingness and responsiveness help to foster intrinsic or selfdetermined motivation that enhances physical activity participation among adolescents.

A final factor to examine when researching adolescent physical activity is attitudes toward physical activity. Investigating attitudes can lead to a more detailed analysis of why adolescents are more inclined to participate in physical activity or why they choose to abstain from physical activity (Markland \& Tobin, 2004). Examining attitudes can also shed light on an individual's level of readiness to initiate a behavior change, such as beginning a physical activity regime or they can shed light into what factors can actually predict physical activity behavior (Godin \& Shephard, 1986). Godin and Shephard (1986) examined attitudes toward physical activity and found that participants who viewed physical activity as a means of health and fitness had higher intentions to exercise than those participants who favored other attitudinal categories. By examining the relationship between parenting style and adolescents' attitudes, we can get a better sense of what family interaction patterns help to foster positive attitudes toward physical activity participation.

Given the paucity of research in this area of physical activity behaviors in youth, the present study extends the literature regarding parenting style and its relationship with physical activity behaviors in adolescents. The present study not only examines parenting style and its relationship with adolescent physical activity participation, but also examines the relationship between parenting style and other factors highly related to physical activity participation, such as motivation and attitude. The current study also focuses specifically on physical activity behaviors and related psychodynamic factors rather than include other dimensions of health such 
as eating habits or measures of body mass. Cultural and demographic factors were also examined to better understand the differences in parenting style across various populations.

Examining the relationship between parenting style and adolescent physical activity behaviors fosters several potential research questions. First, what is the relationship between parenting style and adolescent physical activity participation? Further, what is the relationship between parenting style and variables related to adolescent physical activity participation such as motivation and attitude? Finally, are there any differences among adolescents in regards to gender or race when examining the influence of parenting style on physical activity participation, motivation, or attitude?

\section{Statement of the Problem}

\section{The Problem}

The purpose of the present study is to further examine the relationship between parenting style and adolescent physical activity behaviors. A secondary purpose of the research is to examine the relationship between parenting style on other variables related to physical activity participation, such as motivation and attitudes. Finally, gender and racial differences in regards to the effects of parenting style on physical activity behaviors among adolescents are examined.

\section{Scope of the Study}

The present study employs a descriptive, correlational design to assess levels of and relationships among physical activity participation, motivation and attitudes towards physical activity, and parenting style. Approximately 250 high school students in grades 9-12 participated in this study. Students were recruited for participation at their high school and all students under the age of 18 were required to obtain informed consent from their legal 
guardian(s), as well as provide their own assent for participation, prior to completing the inventories. The consent form was sent home either through the mail or with the students and was returned to the researcher by the designated deadline.

After returning their informed consent form to the researcher, students completed the Parental Authority Questionnaire (PAQ; Buri, 1991) and the Parental Nurturance Scale (PNS;

Buri, 1989) to assess the parenting style of each their male and female caregiver. Students also completed the Godin Leisure-Time Exercise Questionnaire (Godin \& Shephard, 1985) to measure physical activity participation, the Children's Attitudes Toward Physical Activity inventory (CATPA; Schutz, Smoll, \& Wood, 1981) to measure attitudes toward physical activity, and the Behavioral Regulation in Exercise Questionaire-2 (BREQ-2; Markland \& Tobin, 2004) to measure motivational aspects of physical activity participation.

\section{Basic Assumptions}

1. The Parental Authority Questionnaire, the Parental Nurturance Scale, the Children's Attitudes toward Physical Activity inventory, the Godin Leisure-Time Questionnaire, and the Behavioral Regulation in Exercise Questionnaire-2 are all psychometrically sound measures for use with adolescents.

2. High-school age students are likely to have developed a better awareness of their relationship with their parents than younger students.

3. High-school students can accurately report their levels of physical activity using a questionnaire.

4. High-school students represent the developmental level of adolescence and for the purpose of this study, the terms 'students' and 'adolescents' can be used interchangeably. 


\section{Limitations of the Study}

1. Because students were providing self-report data, they might be inclined to provide socially desirable responses rather than a true reflection of their perception of parenting style and physical activity levels.

2. Because the study incorporated data only from high-school students, results may not be generalizable to the child-parent relationship at other age levels (e.g., elementary students, younger children).

3. Physical activity participation was measured by a self-report inventory rather than more detailed objective measurements such as accelerometers or heart-rate monitors.

\section{Definition of Terms}

Parenting style: a classification of parenting behavior that describes how parents balance and reconcile the joint needs of children for nurturance and limit-setting (Baumrind, 1991). Physical activity: any bodily movement resulting in energy expenditure (Sirard \& Pate, 2001). Motivation: a multidimensional concept that resides along a continuum of self-determination ranging from amotivation through intrinsic motivation (Gillison, Standage, \& Skevington, 2006). Attitude: the perceived instrumental value held for seven subsets or dimensions of physical activity (Schutz, Smoll, \& Wood, 1981).

\section{Significance of the Study}

The present study examined the relationship between parenting style and adolescent physical activity behaviors. Additionally, the relationship between parenting style and adolescents' attitudes toward physical activity and their motivation to participate in physical activity was examined. Previous research has found that parenting style has an influence on some health-related behaviors in children, but the exact relationship between parenting style and 
adolescent physical activity participation has not yet been established (Berge, Wall, Loth, \& Neumark-Sztainer, 2010). The present study adds to the literature by providing an analysis of the relationship between parenting style and adolescents' levels of physical activity as well as an analysis of factors related to physical activity such as attitude and motivation.

Examining these factors is extremely important in light of the increasing incidence of childhood obesity. The Center for Disease Control and Prevention (CDC) reported that an estimated 17 percent of children and adolescents ages 2-19 are obese (Center, 2010). When children become obese, the number of risk factors for cardiovascular disease and Type 2 diabetes increase and these children are more likely to be obese even as adults. Because of the numerous health risks that come with obesity, it is extremely important to identify factors that will help increase the amount of physical activity participation in youth. This study helps contribute to this knowledge by examining the right combination of parenting style behaviors as well as clues as to how to foster the appropriate motivation and attitudes needed for adolescents to become more physically active. 


\section{Chapter 2 - Review of the Literature}

\section{Introduction}

The concept of parenting style has long been researched in terms of the impact that differing rearing practices can have on children while growing up within the family and into the future as they become adults and possibly parents themselves. Varying the amount of support and discipline that children receive from parents or guardians can impact the development of children in emotional, cognitive, and social domains. An additional area of development that is newer to the study of parenting style is the aspect of health-related behaviors. The present study examined the effects of parenting style on adolescent physical activity behaviors as well as other psychodynamic variables related to physical activity. As such, the present review will examine literature pertaining to parenting style, parental effects on physical activity behaviors, and a review of how motivation and attitude can also be influential in adolescent physical activity participation.

\section{Parenting Style}

\section{Types of Parenting Style}

Parenting style was conceptualized in the early 1970s by Diane Baumrind (1971) and has played a significant role in the child development research ever since. Baumrind $(1966 ; 1971)$ originally defined three distinct parenting styles based on her observations and research, but later updated to include a fourth parenting style (1991). Baumrind $(1966 ; 1971 ; 1991)$ conceptualized parenting style based on two dimensions of authority: demandingness and responsiveness. The dimension of demandingness refers to the discipline and expectations a parent has for their child and how they enforce these demands to their child; the dimension of responsiveness refers to the 
level of support and individuality that a parent fosters for their children (Baumrind, 1991).

Parenting style can be measured on each of these dimensions yielding either a high or a low score to create four orthogonal groups (see Table 2.1). Each one of these groups can be identified as one of four parenting styles: authoritative, authoritarian, permissive, and rejectingneglecting (disengaged).

\section{Table 2.1 Parenting Style Dimensions}

Parenting Style

Authoritative

Authoritarian

Permissive

Rejecting-Neglecting

\begin{tabular}{cc}
\multicolumn{2}{c}{ Dimension } \\
Demandingness & Responsiveness \\
\cline { 2 - 2 } High & High \\
High & Low \\
Low & High \\
Low & Low
\end{tabular}

Baumrind $(1971 ; 1991)$ provided definitions for each of the four distinct parenting styles. Authoritative parents typically score high on both the demandingness and the responsiveness dimensions of parenting behaviors. While they are demanding, they also value the rights of their children and use reasoning over physical punishment. Authoritative parents will often control their children by explaining rules or decisions and by reasoning through a two-way conversation style rather than dictating to their children the rules without any explanation or room for compromise. Authoritative parents also set high standards for their children's behavior and encourage independence in a supporting environment. Contrastingly, authoritarian parents have been found to be high on the demandingness dimension but low on the responsiveness dimension. They value obedience and order, and they provide a clear set of rules and monitor their children's behavior closely. These parents are very status-oriented and often believe that their rules should be followed simply because they are the authority. While authoritative parents use reasoning and are free to talk openly with their children, authoritarian parents are more likely 
to use punitive measures and not encourage verbal exchange between themselves and their children. Permissive parents are low on the demandingness dimension but high in the responsiveness dimension. While they foster self-regulation and a considerable amount of independence within their children, they lack rules or expectations and they avoid confrontation with their children. Often permissive parents believe that their children should learn through their own experiences and thus, they give their children a lot of freedom to determine their own activities. However, permissive parents often do not demand the same levels of achievement or mature behavior that authoritative or authoritarian parents do. Finally, rejecting-neglecting (sometimes referred to as disengaged) parents are low on both dimensions of parenting style. These characteristics typically involve failing to provide structure or support for their children in either an actively rejecting or neglecting pattern of behavior. Many of these parents may completely fail to embrace their roles and responsibilities as a parent altogether.

\section{Parenting Style and its Relationship to Aspects of Development}

Since the conceptualization of parenting style and the four distinct patterns of parenting behavior were defined, a significant amount of research has been done examining the relationship between parenting style and aspects of development within children and adolescents. For example, when a sample of college students (mean age $=19.1$ years) rated their levels of self-esteem as well as their parents' levels of nurturance and authority, higher self-esteem was found to be related to higher levels of both mothers' and fathers' nurturance as well as parental authoritativeness (Buri, 1989). However, parental authoritarianism was found to be associated with lower levels of self-esteem. This indicates that an authoritative parenting style as well as high levels of nurturance (e.g., not operating from a neglecting or rejecting parenting style) can help to foster higher self-esteem in late adolescence. Determining ways to enhance self-esteem 
in adolescents and young adults can be extremely beneficial as this developmental period is often when children struggle with the ability to accept who they are and embrace their identity.

Parenting style has also been examined in relation to risk-behaviors in adolescents. Baumrind (1991) investigated the relationship of parenting style and adolescent substance abuse with a sample of 15 -year-old children. The results indicated that an authoritative parenting style can help to reduce the likelihood of adolescents using drugs, in addition to enhancing their cognitive and social competence. Baumrind (1991) suggests that those parents who operate in an authoritative style are able to protect their adolescents from dysfunctional risk-taking behavior while still fostering assertiveness and optimism, characteristics that are not often found in authoritarian homes (p. 90). It seems that high demands and high support and responsiveness as is found in authoritative parenting styles helps adolescents to realize the high expectations their parents have for them as well as provides them with the support they need when adolescents are faced with decisions that could potentially be risky or detrimental to their well-being.

An additional study examined several other risk-factors in adolescents and the relationship that these factors had with parenting style. In a recent meta-analysis, Newman, Harrison, Dashiff, and Davies (2008) reviewed studies conducted between 1996-2007 that examined the relationship between parenting styles and six priority adolescent risk behaviors as identified by the Centers for Disease Control and Prevention (CDC). The six risk behavior domains are: behaviors that contribute to unintentional injuries and violence, tobacco use, alcohol and other drug use, sexual behaviors that contribute to unintended pregnancy and sexually transmitted diseases, unhealthy dietary behaviors, and physical inactivity (Newman et al., 2008). The review of these six areas found that an authoritative parenting style was consistently associated with a higher level of protective factors and a lower level of risk 
behaviors in adolescents across five of the six domains. The area that did not match this finding was physical activity because there was a lack of evidence and research done on the effects of parenting style on physical activity in adolescents.

While much of the research points to the benefits of an authoritative parenting style on fostering competent children who are more likely to not engage in risky behaviors, it is important to realize that cultural differences within families can greatly impact the generalizability of these results. Darling and Steinberg (1993) proposed that the definitions of the distinct parenting styles as proposed by Baumrind $(1971 ; 1991)$ are representative of the socialization process found in dominant cultures in the United States, but they do not incorporate socialization processes that might be found in other cultures. For this reason, the authors proposed that parenting style be conceptualized more as a context and that cultural factors should be examined to gain an accurate picture of socialization practices in all cultures and family dynamics. The current study will build on the literature of research regarding the relationship between parenting style and the development of children while also examining and reporting differences among participants to better understand various family dynamics and cultures.

\section{Parental Effects on Child and Adolescent Physical Activity Behaviors}

An additional area of research on the effects of parenting style and child development is the physical health of the child. With the increasing amount of children and adolescents who are classified as obese (CDC, 2010), research has looked at ways in which parents can help to increase physical activity in children to decrease the time spent in sedentary activities. Loprinzi and Trost (2010) conducted a study in which they examined the relationships between child physical activity participation and parental physical activity, parental enjoyment of physical activity, parents' perceived importance of physical activity, and parents' perceptions of their 
child's physical activity competence. The children in this study were between the ages of 2 to 5 and enrolled in a child care facility (mean age $=3.7$ ). Results from this study indicated that children's levels of physical activity within the home were highly correlated with parental support for physical activity (Loprinzi \& Trost, 2010). This suggests that the more parents are expressing their support for their children to participate in physical activity, the more likely children are to participate in physical activity. For young children, this might require the parents to be more involved in the physical activity behaviors themselves since young children often must be supervised while playing or participating in physical activity. It is important to examine additional research on older children and adolescents who are more independent and have more freedom to participate in physical activity when their parents are not necessarily participating with them.

Research indicates that parental support for their children's physical activity is still highly related to physical activity participation by the child even into their adolescent years. Gustafson and Rhodes (2006) reviewed 34 research studies that looked at parental influences on physical activity participation in children ages 3 through 12 . Results from this review indicated that 19 out of the 34 studies examined parental support in relation to child physical activity participation and 18 out of the 19 studies found that a positive association existed between parental support and child physical activity participation (Gustafson \& Rhodes, 2006). The authors report that the one study that did not find a positive association between these two variables used a less reliable measure which could have impacted the results. Clearly, the amount of parental support can highly impact the amount of physical activity that children participate in.

Several other studies have found that parental support is a key ingredient in the socialization of child and adolescent physical activity. Pugliese and Tinsley (2007) conducted a 
review on child and adolescent physical activity behaviors and their relation to parental socialization behaviors. Results from this study indicated a moderate positive relation between parental support, modeling behavior, and child and adolescent physical activity levels (Pugliese \& Tinsley). Van Der Horst, Paw, Twisk, and Van Mechelen (2007) also replicated the finding that parental support is positively associated with physical activity for children between 4 and 12 years of age after reviewing 60 studies in the literature on correlates of physical activity in youth. Additionally, Brustad and Partridge (2002) emphasized the impact that parental socialization can have on youth physical activity participation and behaviors. These authors reported the importance of parental encouragement and support for their children's physical activity endeavors even when they are not successful to continue to boost childhood participation in physical activity.

More recently, Berge, Wall, Loth, and Neumark-Sztainer (2010) conducted a longitudinal study that examined parenting style and adolescent weight and weight-related behaviors at two points in time. In this study, adolescents rated their perceptions of their parents' parenting style at time 1 (mean age $=12.8$ years) and then they reported their body mass index $(\mathrm{BMI})$, dietary intake, and physical activity levels at time 2 (mean age $=17.2$ years). Results indicated that while a maternal authoritative parenting style predicted a lower BMI in both males and females and a permissive paternal parenting style predicted more fruit and vegetable intake in females, there was not a significant association between any parenting style and physical activity participation. Given the abundance of research on the importance of parental support and childhood physical activity participation, the present study will continue to probe the relationship between specific parenting styles and physical activity due to the element of support and responsiveness that is found within the parenting style dimensions. 


\section{Physical Activity Motivation and Attitudes}

Two additional factors that are highly related to physical activity participation are motivation and attitude. Having motivation to engage in physical activity and having a positive attitude regarding physical activity participation are key elements in increasing the time spent being active.

\section{Motivation and Self-Determination Theory}

Motivation to participate in physical activity is a key factor in determining why individuals participate in or refrain from physical activity. The self-determination theory (SDT; Deci \& Ryan, 1985) has been a widely utilized theory in the study of motivation and has recently been used as a theoretical approach to examining adolescent physical activity. When measuring motivation from a SDT approach, motivation is placed on a continuum ranging from amotivation to intrinsic motivation, with four extrinsic motivational factors falling between the two (see Figure 2.1). Biddle (1999) outlined the four main types of extrinsic motivation in terms of behavioral regulation: external regulation, introjected regulation, identified regulation, and integrated regulation. External regulation is defined by outside rewards or threats such as coercion or pressure from other people. External regulation is the closest of the four types of extrinsic motivation to the amotivation end of the continuum. Next, introjected regulation is when individuals act because they want to avoid negative feelings or seek approval from others. Identified regulation is when the behavior is motivated by an appreciation of the outcomes of participation, such as health improvement. Finally, and closest to intrinsic motivation on the continuum, integrated regulation is when the individual participates in behaviors because they consider them a part of their self or identity (Biddle). SDT is based on the principle that selfdetermination, or actions motivated by intrinsic goals, leads to more positive behavioral 
outcomes. SDT proposes that by fostering autonomous and intrinsic motivational intentions and goals, behaviors such as physical activity can be increased.

Figure 2.1 Self-Determination Theory Continuum of Motivation

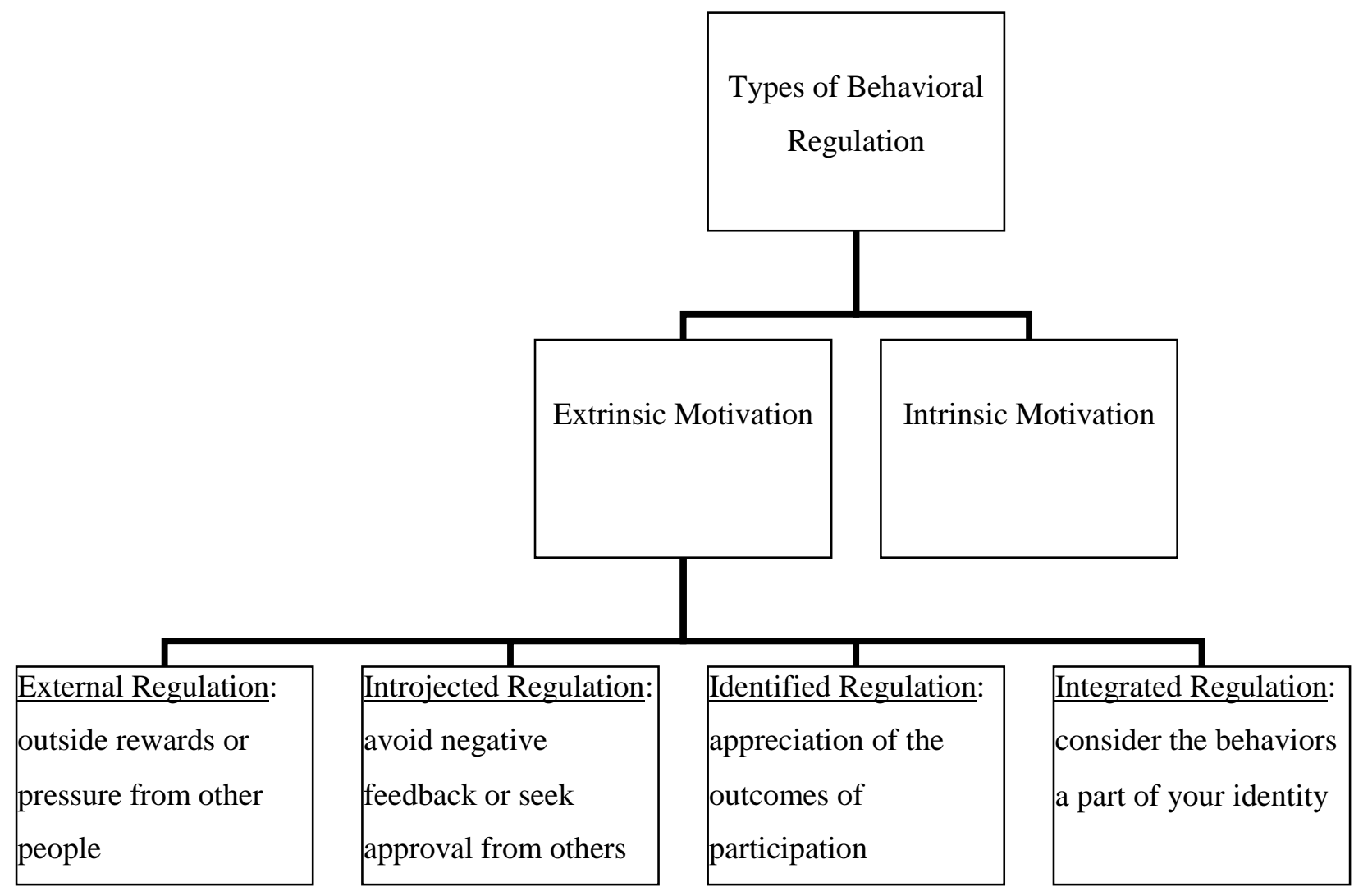

Chatzisarantis, Biddle, and Meek (1997) assessed motivation to participate in leisure-time exercise with 11-to-15-year-olds and found that autonomous intentions to participate in the physical activity predict actual participation more so than controlling intentions. These autonomous intentions are highly aligned with intrinsic goals and lend support to the importance of self-determined motivation. Similar results were produced in a study by Spray, John-Wang, Biddle, and Chatzisarantis (2006) when they utilized SDT to assess adolescents' (mean age = 13.43 years) enjoyment, free-choice behavior, and performance in relation to a physical activity task. Autonomous intentions to participate in the physical activity task were associated with higher enjoyment, persisted longer at the task, and performed better. As individuals become less 
extrinsically motivated and increase in their levels of intrinsic or self-determined motivation, their level of autonomy also increases. Thus, autonomy is a critical element in self-determined motivation and can help to foster higher levels of intrinsic motivation. These studies provide support to these effects in adolescents and that even at this age, individuals can experience levels of intrinsic or self-determined motivation.

Additionally, Gillison, Standage, and Skevington (2006) utilized SDT when examining relationships between adolescents' exercise behavior and exercise motivation. This study reported that extrinsic motivation was more common when adolescents (mean age $=14.06$ years) perceived themselves to be overweight or pressured to lose weight, and these extrinsic goals negatively predicted self-determined motivation. This study also found that intrinsic goals positively predicted self-determined motivation which in turn positively predicted exercise behavior (Gillison et al., 2006). It seems that by enhancing self-determined motivation and intrinsic goals pertaining to physical activity, adolescents are more likely to participate in exercise behavior. The present study will attempt to identify what parenting style variables can help to boost these intrinsic goals, self-determination, and thus, physical activity participation.

\section{Attitudes toward Physical Activity}

Measuring individuals' attitudes toward physical activity is also helpful in examining why some choose to participate and why others do not. Godin and Shephard (1986) established the need for assessing attitudes when studying physical activity behaviors. This study found positive correlations between a measure of attitude and intentions to exercise. Kohl and Hobbs (1998) also emphasized the importance of fostering a positive attitude toward physical activity to increase the amount of participation in physical activities. They reviewed the literature on 
potential determinants of physical activity in children and adolescents and found that attitude does influence the incidence of physical activity behaviors.

Weiss and Williams (2004) reviewed the literature regarding reasons that youth participate in sports and found that these reasons can be categorized into three areas: physical competence/adequacy, social acceptance and approval, and enjoyment. Each of these areas encompasses many factors and in general, more positive attitudes regarding these areas and factors leads to higher levels of participation and increased adherence in sport. From these findings, it is apparent that youth do have opinions about why they might participate in sports or physical activity and fostering positive attitudes regarding these areas or promoting physical activity using these three areas as a basis for engaging in physical activity might lead to an increase in physical activity participation in adolescents.

The examination of attitude toward physical activity can help to discover ways in which to foster positive attitudes toward physical activity, and thus increase the amount of physical activity participation in children and adolescents. The present study will attempt to discover relationships between attitudes and physical activity as well as between parenting style and attitude to determine which parenting styles help to foster positive attitudes and increasing physical activity behaviors.

\section{Conclusion}

After a review of the literature on the effects of parenting style on adolescent physical activity behaviors, the need for more research in this area is apparent. The present study was designed to replicate key parts of previous research as well as add new components to help better understand how the parent-child relationship can foster or hinder physical activity participation. First, the present study continues the research regarding the relationship between parenting style 
and physical activity participation in adolescents. Second, the present study incorporates the variables of motivation and attitudes to further examine and explore how to utilize effective parenting strategies to boost motivation and positive attitudes toward physical activity. Finally, the present study adds to the literature by examining differences in terms of gender, age, race, and ethnicity to provide a look at ways in which culture can affect the relationship between parents and adolescent physical activity behaviors. 


\section{Chapter 3 - Methodology}

\section{Introduction}

The present study utilized several self-report measures to assess the relationships between parenting style dimensions and adolescent physical activity participation, motivation to be physically active, and attitudes towards physical activity. The research design including the participants, instrumentation, procedures, and data analyses will be outlined and discussed within the following section.

\section{Participants}

The participants in this study were recruited from three high school settings in the northeast region of Kansas. The number of participants in this study totaled 259. Of those participants, 130 were male, 121 were female, and 8 participants did not specify their gender. The age range of the participants was from 14-19 years of age and the mean age of the participants was 16.1 years of age. Of those participants who reported their race, $216(83.4 \%)$ participants were White, 21 (8.1\%) participants were African American, three $(1.2 \%)$ participants were either Asian or Native American, and 15 (5.8\%) participants marked other. Of those participants who reported their ethnicity, 18 participants $(6.9 \%)$ were Hispanic or Latino, 230 participants $(88.8 \%)$ were Not Hispanic or Latino.

\section{Research Design}

\section{Variables}

The present study incorporated several variables in an attempt to explore the relationships between parenting style and adolescent physical activity-related behaviors. Demographic 
variables to be examined included the gender, age, race, and ethnicity of the participants.

Research variables included both the male and female care-giver's parenting style as assessed by the student, the male and female care-giver's nurturance level as assessed by the student, the amount of physical activity that each student participates in, the students' motivation to participate in physical activity, and the students' attitudes toward physical activity.

\section{Limitations}

A limitation of this study is that the students provided self-report data which can sometimes lead participants to provide socially desirable responses rather than honest or accurate answers. Another limitation is that high-school students comprised the sample in this study; therefore, the results may not be generalizable to other populations such as young children or elementary students. Another threat to the generalizability of the results of the study is the fact that the sample was a convenience sample rather than utilizing a random sampling technique. The use of a convenience sample also introduces the threat of bias to the results of the study. Additionally, physical activity participation was measured by a self-report inventory rather than objectives measures such as a heart rate monitor or an accelerometer. This study also had a limited amount of variability in the race and ethnicity of the participants, making it difficult to examine potential differences between participants of varied races or ethnicities.

\section{Strengths}

A strength of the present study is that it incorporated not only a measure of physical activity participation, but also measures of psychosocial variables related to physical activity participation, specifically motivation and attitudes. While motivation and attitude have been researched in relation to physical activity participation, there has not been any research conducted that examined the relationship of parenting style to these variables. An additional 
strength of the present study is the ability to explore and discover ways to enhance physical activity participation in adolescents and thus decrease the incidence of sedentary behaviors in youth.

\section{Instrumentation}

\section{Parental Authority Questionnaire (PAQ)}

The variable of parenting style was assessed using the Parental Authority Questionnaire (PAQ; Buri, 1991). This measure consists of 30 items and was completed by each participant twice - once in terms of their female caregiver, and once in terms of their male care-giver. Participants indicated who they considered to be their primary male caregiver or female caregiver (e.g., father/mother, grandfather/grandmother, uncle/aunt, step-father/step-mother, or other) and were asked to think about this male or female caregiver as they completed the questionnaire (see Appendix A and B). For the present study, about $76 \%$ of the participants chose their father as their primary male caregiver and about $96 \%$ chose their mother as their primary female caregiver. The items on this measure are rated on a 5-point scale $(1=$ strongly disagree; $5=$ strongly agree) and scores for this measure are found by totaling the scores on the items pertaining to a particular parenting style. This measure provides scores for three of the four distinct parenting styles: authoritative, authoritarian, and permissive. A sample item corresponding to an authoritative parenting style is: “As I was growing up, once family policy had been established, my male/female caregiver discussed the reasoning behind the policy with the children in the family." A sample item corresponding to an authoritarian parenting style is: "Whenever my male/female caregiver told me to do something as I was growing up, he/she expected me to do it immediately without asking any questions." A sample item corresponding to a permissive parenting style is: "As I was growing up, my male/female caregiver allowed me 
to decide most things for myself without a lot of direction from him/her." Adequate internal consistency reliability levels were established during the measure's development and ranged from .74 to .87. Test-retest reliability levels ranged from .77 to .92 for adolescents (Buri, 1991). In the present study, internal consistency reliability levels ranged from .70-.87 for adolescents' perceptions of their male caregiver and from .69-.82 for their perceptions of their female caregiver (see Table 3.1).

\section{Parental Nurturance Scale (PNS)}

The final parenting style, rejecting-neglecting, was assessed through the Parental Nurturance Scale (PNS; Buri, 1989). This scale consists of 24 items that are rated on a 5-point scale $(1=$ strongly disagree; $5=$ strongly agree $)$. The PNS was combined with the PAQ during data collection since they utilize the same rating scale. After combining the scales, the first 30 items on the measure correspond to the PAQ and the last 24 items correspond to the PNS (see Appendix A and B). Scores on this measure are calculated by totaling all the item scores. Each student completed two forms of the PNS; one form assessed their female caregiver's nurturance, and the other assessed their male caregiver's nurturance. A sample item on this scale is: "My male/female caregiver expresses his/her warmth and affection for me." Internal consistency levels for an adolescent sample were .95 for female caregiver's PNS and .93 for male caregiver's PNS (Buri, 1989). In the present study, internal consistency reliability levels were .97 when participants rated their malecare giver's nurturance and .95 when participants rated their female caregiver's nurturance (see Table 3.1). An additional item was added at the end of this scale to assess the participants' perceptions of their male or female caregiver's level of physical activity participation. Participants circled "yes" or "no" to the question: "Do you think this female care giver participates in at least 30 minutes of moderate cardiovascular exercise for five or more 
days each week?" This statement assesses whether or not the participants felt their care-givers were meeting the physical activity standards as set by the American College of Sports Medicine (ACSM, 2007).

Table 3.1 Internal Reliability Levels for PAQ and PNS

\begin{tabular}{lc}
\multicolumn{1}{c}{ Measure } & Cronbach's Alpha Level \\
\cline { 2 - 2 } Male Care-Giver Authoritative & .86 \\
Male Care-Giver Authoritarian & .87 \\
Male Care-Giver Permissive & .70 \\
Male Care-Giver Nurturance & .97 \\
Female Care-Giver Authoritative & .82 \\
Female Care-Giver Authoritarian & .82 \\
Female Care-Giver Permissive & .69 \\
Female Care-Giver Nurturance & .95
\end{tabular}

\section{Godin Leisure-Time Exercise Questionnaire}

Adolescent physical activity participation was assessed through the Godin Leisure-Time Exercise Questionnaire (Godin \& Shephard, 1985). This measure asks participants to indicate how often in a typical week they participate in mild, moderate, and strenuous levels of physical activity. Examples of each of these activities are given and participants indicated how many days per week they spent participating in the different levels of exercise for at least 60 minutes. The American College of Sports Medicine recommends that children and adolescents participate in at least 60 minutes of moderate physical activity each day (ACSM, 2006). For the present study, participants were asked to include any physical activity that they do outside of school time, but to also include school-associated activities such as a sport team. However, it is important to note that the examples given reflected leisure-time activities and so it is uncertain whether participants included all occupational, household, and/or transportation physical activity in addition to their school and after-school physical activity. This measure has been shown to be reliable both over time, and has also been shown to have concurrent validity with physiological 
measures of exercise such as VO2 max levels and body fat percentages. Godin and Shephard reported a .74 test-retest reliability level for the questionnaire with adults and Sallis, Buono, Roby, Micale, and Nelson (1993) reported a test-retest reliability level of .96 with a sample of $11^{\text {th }}$ grade students. For the present study, three additional items were added to differentiate between students who were participating in physical activity as part of a class or sport at school and those who were not (see Appendix C).

\section{Children's Attitudes toward Physical Activity (CATPA)}

Attitudes toward physical activity were assessed through the Children's Attitudes toward Physical Activity scale (CATPA; Schutz, Smoll, \& Wood, 1981). This measure required participants to rate seven dimensions of physical activity on 5-point scale for each of five bipolar adjectives. The seven dimensions of physical activity are: social growth, social continuation, health and fitness, vertigo, aesthetic, catharsis, and ascetic. Each of these dimensions was rated through five bi-polar adjective pairs (i.e. good/bad, of no use/useful, not pleasant/pleasant, nice/awful, and happy/sad; see Appendix D). Scores are derived by totaling the number that corresponds with the blank that is marked between the two bi-polar adjectives (i.e., 0 for the middle blank, +1 for the next blank closest to the positive adjective, -1 for the next blank closest to the negative adjective, +2 for the blank closest to the positive adjective, and -2 for the blank closest to the negative attitude). Internal consistency levels for each dimension were all approximately .80 when used with an $11^{\text {th }}$ grade sample (Schutz, Smoll, \& Wood). For the present study, internal consistency levels for the seven dimensions ranged from .82 to .93 (see Table 3.2). 
Table 3.2 Internal Reliability Levels for CATPA

\begin{tabular}{lc}
\multicolumn{1}{r}{ CATPA Subscale } & Cronbach's Alpha Level \\
\cline { 2 - 2 } Social Growth & .85 \\
Social Relations & .87 \\
Health and Fitness & .82 \\
Vertigo & .93 \\
Aesthetic & .93 \\
Catharsis & .86 \\
Ascetic & .91
\end{tabular}

\section{Behavioral Regulation in Exercise Questionaire-2 (BREQ-2)}

Motivation toward physical activity was assessed through the Behavioral Regulation in Exercise Questionnaire-2 (BREQ-2; Markland \& Tobin, 2004; see Appendix E). This measure is based on the self-determination theory of motivation (SDT; Deci \& Ryan, 1985) and incorporates five different forms of behavioral regulation: amotivation, external, introjected, identified, and intrinsic. This form of the questionnaire was developed from the original Behavioral Regulation in Exercise Questionnaire (Mullan, Markland, \& Ingledew, 1997) and added the subscale measuring amotivation. This measure has 19 items which are rated on a 5point scale $(0=$ not true for me; $4=$ very true for me $)$. Scores are derived for each form of regulation by totaling the corresponding items for that form. Internal consistency levels for each subscale or behavioral regulation type ranged from .73 to .86 (Markland \& Tobin, 2004). A sample item assessing external behavioral regulation is: "I exercise because other people say I should." For the present study, internal consistency levels for the five forms of regulation ranged from .80 to .93 (see Table 3.3).

\section{Table 3.3 Internal Reliability Levels for BREQ-2}

Amotivation BREQ-2 Subscale

External Regulation

Introjected Regulation

Identified Regulation
Cronbach's Alpha Level

.88

.81

.80

.81 


\section{Procedures}

\section{Parent Procedures}

Approximately two weeks before data was collected from the students, a parental consent form (see Appendix E) was sent either directly to the home in the mail or with the student. Parents were asked to read and sign the consent form and students were required to return this form in order to be able to participate in the completion of the measures at the time of data collection. Approximately twice a week, the research team sent electronic reminders to the teachers to encourage them to remind their students to bring back these forms so they could participate in the study.

\section{Student Procedures}

At two of the three data collection sites, students were asked to deliver the parental consent form to their parents and bring it back to school within the designated time period. At the third data collection site, the parental consent forms were mailed home so the students were only required to return the form to school. This decision was based on the recommendation of the school's principal. On the day of data collection, students were asked to provide their assent by signing the consent form as well. By signing the form, students agreed to their voluntary participation in the study and were informed as to what the study entailed. The consent forms were collected before the measures were distributed so that no identifying information was associated with the completed measures. A researcher distributed copies of the five questionnaires to the participating students and asked the students to read the directions at the top of each questionnaire and respond to every item to the best of their ability. The researcher also 
informed the students that there are no right or wrong answers and that it was very important for them to be as honest as possible while completing the questionnaires. The researcher also announced that the students should not write their names on any of the measures and that they may stop participation at any time without any penalty. Once finished, students returned their completed questionnaires to the researcher and were thanked greatly for their participation and time. These questionnaires were counterbalanced in order to eliminate any effects of fatigue or order of inventory completion.

Contact with each of the high school principals and participating teachers was made before the parental consent forms were distributed to the teachers, students, or parents. The principals and teachers also helped give input on the best way to collect data at their particular school. Students completed the questionnaires as a part of a regular scheduled class. At two of the data collection sites, students participated as part of their English class and at one data collection site, students participated as part of their Biology class. It took approximately 30-40 minutes for participants to complete the measures.

\section{Potential Concerns}

A significant concern in the present study was the requirement that students take the informed consent form home for their parents to sign and then bring the form back to the school setting. This was problematic because many students either forget or neglected to have the form signed by their parents in the allotted time before data collection. While approximately 760 students were invited to participate in the study, only 259 students successfully completed the measures and were included in the data analyses. 


\section{Hypotheses}

Based on the previous research findings that have demonstrated a positive relationship between an authoritative parenting style and positive social, cognitive, and emotional development (Baumrind, 1991; Buri, 1989; Newman, Harrison, Dashiff, \& Davies, 2008;) as well as the research that indicates the positive relationship between parental support and levels of childhood physical activity (Brustad \& Partridge, 2002; Gustafson \& Rhodes, 2006; Kohl \& Hobbs, 1998; Pugliese \& Tinsley, 2007), it was hypothesized that an authoritative parenting style would also be positively related to higher levels of physical activity in adolescents $\left(\mathrm{H}_{1} 1\right)$. A second hypothesis was that an authoritative parenting style would be positively related with selfdetermined or intrinsic motivational goals and inversely related to extrinsic motivational goals $\left(\mathrm{H}_{1} 2\right)$. Third, it was hypothesized that an authoritative parenting style would be positively related to more favorable attitudes toward physical activity $\left(\mathrm{H}_{1} 3\right)$. Fourth, it was hypothesized that both self-determined motivation and favorable attitudes toward physical activity would be related to a higher amount of physical activity participation among adolescents $\left(\mathrm{H}_{1} 4\right)$.

Additionally, it was hypothesized that there would be differences between males and females on their assessment of parenting style as well as their levels of motivation and attitudes, but the direction of these differences could not be specified at this time given the paucity of research that has examined this area $\left(\mathrm{H}_{1} 5\right)$. Similarly, it was hypothesized that there would be differences between racial and ethnic groups on their assessment of parenting style, but these differences could not be specified due to the novelty of this line of research $\left(\mathrm{H}_{1} 6\right)$. Finally, it was hypothesized that there would be differences in the amount of variance each of the predictor variables of gender, parenting style, motivation, and attitudes had on the criterion variable of 
physical activity participation, and that these variables would be significant predictors of physical activity participation. $\left(\mathrm{H}_{1} 7\right)$.

\section{Data Analyses}

SPSS version 19.0 was used to perform all statistical analyses. Internal consistency levels were assessed to examine the reliability of the measures in the present study. To test research hypotheses one through four, a bi-variate correlation matrix was conducted separately for males and females to look at the relationships between parenting style and adolescent physical activity participation, motivation, and attitudes. This analysis also examined the relationships between motivation and attitudes toward physical activity and adolescent physical activity participation separately for males and females. To test research hypothesis five, two, one-way MANOVAs were conducted to assess differences between males and females on their assessment of parenting style. One MANOVA was conducted to assess differences between males and females on their male caregiver's parenting style and one MANOVA was conducted to assess differences between males and females on their female caregiver's parenting style. To test the second part of research hypothesis five, two additional MANOVAs were conducted to assess differences between males and females on their assessment of motivation and attitudes toward physical activity. One MANOVA examined differences between males and females regarding motivation toward physical activity and a second MANOVA examined differences between males and females regarding attitudes toward physical activity. To test research hypothesis six, a MANOVA was conducted to examine differences between racial groups on their assessment of parenting style. Finally, to test research hypothesis seven, six multipleregression analyses were run to examine the effects of significantly correlated predictor variables 
on the criterion variable of physical activity participation. Regression analyses were conducted separately for males and females.

\section{Results}

The first hypothesis was that an authoritative parenting style would be positively related to physical activity participation in adolescents. For male participants, an authoritative parenting style from the male caregiver was not related to strenuous, moderate or mild physical activity (see Table 3.4). However, a permissive parenting style from the male caregiver was related to both strenuous $(r=.20 ; p<.05)$ and moderate $(r=.22 ; p<.05)$ physical activity. Additionally for male participants, an authoritative parenting style from the female caregiver was not related to strenuous, moderate, or mild physical activity (see Table 3.5). However, a permissive parenting style from the female caregiver was related to moderate physical activity participation $(r=.20 ; p<.05)$ and high levels of nurturance from the female caregiver were related to moderate physical activity participation $(r=.19 ; p<.05)$. For female participants, an authoritative parenting style from the male caregiver was related to moderate physical activity participation $(r=.31 ; p<.01)$ and mild physical activity participation $(r=.19 ; p<.05$; see Table 3.4). High levels of nurturance from the male caregiver were also related to moderate physical activity participation in female participants $(r=.32 ; p<.01)$. An authoritative parenting style from the female caregiver was related to moderate $(r=.20 ; p<.05)$ and mild $(r=.22 ; p<.05)$ physical activity for female participants (see Table 3.5). 
Table 3.4 Correlations for Male Caregiver's Parenting Style and Physical Activity

$\begin{array}{lccccccc} & \begin{array}{c}\text { Male } \\ \text { Authoritative }\end{array} & \begin{array}{c}\text { Male } \\ \text { Authoritarian } \\ \text { Male }\end{array} & \begin{array}{c}\text { Male } \\ \text { Permissive }\end{array} & \begin{array}{c}\text { Male } \\ \text { Nurturance }\end{array} & \text { Strenuous } & \text { Moderate } & \text { Mild } \\ \begin{array}{l}\text { Authoritative } \\ \text { Male }\end{array} & 1 & .01 & .13 & .64^{* *} & .04 & .09 & .12 \\ \begin{array}{l}\text { Authoritarian } \\ \text { Male }\end{array} & .28^{* *} & 1 & -.38^{* *} & -.17 & .13 & -.00 & .12 \\ \begin{array}{l}\text { Permissive } \\ \text { Male }\end{array} & .17 & -.44^{* *} & 1 & -.01 & .20^{*} & .22^{*} & -.07 \\ \begin{array}{l}\text { Nurturance } \\ \text { Strenuous }\end{array} & .77^{* *} & -.29^{* *} & .13 & 1 & .02 & .04 & .17 \\ \text { Moderate } & -.03 & .12 & -.06 & -.03 & 1 & .24 * * & -.02 \\ \text { Mild } & .31^{* *} & -.07 & .10 & .32^{* *} & .43^{* *} & 1 & .39 * * \\ & .19^{*} & .11 & .00 & .10 & .25^{* *} & .40^{* *} & 1\end{array}$

${ }^{*} p<.05 ; * * p<.01$; All correlations above the diagonal line correspond to male participants and all correlations below the diagonal line correspond to female participants.

Table 3.5 Correlations for Female Caregiver's Parenting Style and Physical Activity

$\begin{array}{lccccccc} & \begin{array}{c}\text { Female } \\ \text { Authoritative }\end{array} & \begin{array}{c}\text { Female } \\ \text { Authoritarian }\end{array} & \begin{array}{c}\text { Female } \\ \text { Permissive }\end{array} & \begin{array}{c}\text { Female } \\ \text { Nurturance }\end{array} & \text { Strenuous } & \text { Moderate } & \text { Mild } \\ \begin{array}{l}\text { Female } \\ \text { Authoritative }\end{array} & 1 & -.01 & .04 & .47^{* *} & -.01 & .16 & .14 \\ \begin{array}{l}\text { Female } \\ \text { Authoritarian }\end{array} & -.21^{*} & 1 & -.45^{* *} & -.21^{*} & .17 & -.10 & .09 \\ \begin{array}{l}\text { Female } \\ \text { Permissive }\end{array} & .20^{*} & -.40^{* *} & 1 & -.01 & .07 & .20^{*} & .04 \\ \begin{array}{l}\text { Female } \\ \text { Nurturance }\end{array} & .73^{* *} & -.44^{* *} & .18 & 1 & .10 & .19^{*} & .13 \\ \begin{array}{l}\text { Strenuous } \\ \text { Moderate }\end{array} & .12 & .13 & -.02 & -.01 & 1 & .24 * * & -.02 \\ \text { Mild } & .20^{*} & -.02 & .09 & .11 & .43^{* *} & 1 & .39^{* *} \\ & .22^{*} & .10 & -.01 & .05 & .25 * * & .40^{* *} & 1\end{array}$

${ }^{*} p<.05 ;{ }^{* *} p<.01$; All correlations above the diagonal line correspond to male participants and all correlations below the diagonal line correspond to female participants.

The second hypothesis was that an authoritative parenting style would be positively related to intrinsic regulation and negatively related to external regulation. For male participants, an authoritative parenting style from the male caregiver was not positively related to intrinsic 
regulation nor was it negatively related to external regulation (see Table 3.6). An authoritative parenting style from the female caregiver was also not positively related to intrinsic regulation nor was it inversely related to external regulation (see Table 3.7) for male participants. For female participants, an authoritative parenting style from the male caregiver was not positively related to intrinsic regulation nor was it inversely related to external regulation (see Table 3.6). An authoritative parenting style from the female caregiver was positively related to intrinsic regulation $(r=.26 ; p<.01)$ but it was not inversely related to external regulation (see Table 3.7$)$. An authoritative parenting style from the female caregiver was also positively related to identified regulation $(r=.36 ; p<.01)$ and introjected regulation $(r=.28 ; p<.01)$. Nurturance from the female caregiver was also positively related to identified regulation $(r=.29 ; p<.01)$ and intrinsic regulation $(r=.25 ; p<.01)$.

\section{Table 3.6 Correlations for Male Caregiver's Parenting Style and Adolescent Motivation}

\begin{tabular}{|c|c|c|c|c|c|c|c|c|c|}
\hline & $\begin{array}{c}\text { Male } \\
\text { Authoritative }\end{array}$ & $\begin{array}{c}\text { Male } \\
\text { Authoritarian }\end{array}$ & $\begin{array}{c}\text { Male } \\
\text { Permissive }\end{array}$ & $\begin{array}{c}\text { Male } \\
\text { Nurturance }\end{array}$ & Amotivation & $\begin{array}{l}\text { External } \\
\text { Regulation }\end{array}$ & $\begin{array}{l}\text { Introjected } \\
\text { Regulation }\end{array}$ & $\begin{array}{l}\text { Identified } \\
\text { Regulation }\end{array}$ & $\begin{array}{c}\text { Intrinsic } \\
\text { Regulation }\end{array}$ \\
\hline $\begin{array}{l}\text { Male } \\
\text { Authoritative }\end{array}$ & 1 & .01 & .13 & $.64 * *$ & .03 & .08 & .14 & .12 & .12 \\
\hline $\begin{array}{l}\text { Male } \\
\text { Authoritarian }\end{array}$ & $-.28 * *$ & 1 & $-.38 * *$ & -.17 & -.05 & .15 & .14 & .06 & -.07 \\
\hline $\begin{array}{l}\text { Male } \\
\text { Permissive }\end{array}$ & .17 & $-.44 * *$ & 1 & -.01 & .06 & .02 & .08 & .10 & .17 \\
\hline $\begin{array}{l}\text { Male } \\
\text { Nurturance }\end{array}$ & $.77 * *$ & $-.29 * *$ & .13 & 1 & -.03 & .06 & .12 & .09 & .11 \\
\hline Amotivation & .07 & -.08 & .12 & -.04 & 1 & $.27 * *$ & $-.23^{*}$ & $-.42 * *$ & $-.50 * *$ \\
\hline $\begin{array}{l}\text { External } \\
\text { Regulation }\end{array}$ & .12 & -.16 & .10 & .09 & $.24 * *$ & 1 & $.23 * *$ & .10 & -.03 \\
\hline $\begin{array}{l}\text { Introjected } \\
\text { Regulation }\end{array}$ & .02 & .08 & -.15 & .02 & -.18 & .13 & 1 & $.60 * *$ & $.45^{* *}$ \\
\hline $\begin{array}{l}\text { Identified } \\
\text { Regulation }\end{array}$ & .07 & .18 & $-.20 *$ & .07 & $-.46^{* *}$ & -.08 & $.63 * *$ & 1 & $.73 * *$ \\
\hline $\begin{array}{l}\text { Intrinsic } \\
\text { Regulation }\end{array}$ & .04 & .19 & -.15 & .03 & $-.48 * *$ & $-.28 * *$ & $.44 * *$ & $.79 * *$ & 1 \\
\hline
\end{tabular}

${ }^{*} p<.05 ; * * p<.01$; All correlations above the diagonal line correspond to male participants and all correlations below the diagonal line correspond to female participants. 


\section{Table 3.7 Correlations for Female Caregiver's Parenting Style and Adolescent Motivation}

\begin{tabular}{|c|c|c|c|c|c|c|c|c|c|}
\hline & $\begin{array}{c}\text { Female } \\
\text { Authoritative }\end{array}$ & $\begin{array}{c}\text { Female } \\
\text { Authoritarian }\end{array}$ & $\begin{array}{c}\text { Female } \\
\text { Permissive }\end{array}$ & $\begin{array}{c}\text { Female } \\
\text { Nurturance }\end{array}$ & Amotivation & $\begin{array}{c}\text { External } \\
\text { Regulation }\end{array}$ & $\begin{array}{l}\text { Introjected } \\
\text { Regulation }\end{array}$ & $\begin{array}{l}\text { Identified } \\
\text { Regulation }\end{array}$ & $\begin{array}{l}\text { Intrinsic } \\
\text { Regulation }\end{array}$ \\
\hline $\begin{array}{l}\text { Female } \\
\text { Authoritative }\end{array}$ & 1 & -.01 & .04 & $.47 * *$ & -.07 & .08 & .14 & .11 & .09 \\
\hline $\begin{array}{l}\text { Female } \\
\text { Authoritarian }\end{array}$ & $-.21 *$ & 1 & $-.45 * *$ & $-.21 *$ & .01 & $.28 * *$ & $.19^{*}$ & .14 & .06 \\
\hline $\begin{array}{l}\text { Female } \\
\text { Permissive }\end{array}$ & $.20 *$ & $-.40 * *$ & 1 & -.01 & -.01 & -.02 & .11 & .02 & -.02 \\
\hline $\begin{array}{l}\text { Female } \\
\text { Nurturance }\end{array}$ & $.73 * *$ & $-.44 * *$ & .18 & 1 & -.12 & .02 & .17 & .13 & .08 \\
\hline Amotivation & -.03 & -.13 & .09 & -.06 & 1 & $.27 * *$ & $-.23 *$ & $-.42 * *$ & $-.50 * *$ \\
\hline $\begin{array}{l}\text { External } \\
\text { Regulation }\end{array}$ & -.06 & .01 & .00 & $-.20 *$ & $.24 * *$ & 1 & $.23 * *$ & .10 & -.03 \\
\hline $\begin{array}{l}\text { Introjected } \\
\text { Regulation }\end{array}$ & $.28 * *$ & .09 & -.07 & .15 & -.18 & .13 & 1 & $.60 * *$ & $.45 * *$ \\
\hline $\begin{array}{l}\text { Identified } \\
\text { Regulation }\end{array}$ & $.36 * *$ & -.02 & -.07 & $.29 * *$ & $-.46 * *$ & -.08 & $.63 * *$ & 1 & $.73 * *$ \\
\hline $\begin{array}{l}\text { Intrinsic } \\
\text { Regulation }\end{array}$ & $.26 * *$ & .03 & -.10 & $.25^{* *}$ & $-.48 * *$ & $-.28 * *$ & $.44 * *$ & $.79 * *$ & 1 \\
\hline
\end{tabular}

$* p<.05 ; * * p<.01$; All correlations above the diagonal line correspond to male participants and all correlations below the diagonal line correspond to female participants.

The third hypothesis was that an authoritative parenting style would be positively related to more favorable attitudes toward physical activity. For male participants, an authoritative parenting style from the male caregiver was positively related to more favorable attitudes regarding participating in physical activity to continue social relations $(r=.25 ; p<.01)$ but was not positively related to any of the other six attitude categories (see Table 3.8). An authoritative parenting style from the female caregiver was positively related to more favorable attitudes regarding participating in physical activity to achieve catharsis $(r=.25 ; p<.01)$ but was not positively related to any of the other six attitude categories (see Table 3.9). For female participants, an authoritative parenting style from the male caregiver was not significantly related to any of the seven attitude sub scales (see Table 3.8). An authoritative parenting style from the female caregiver was positively related to more favorable attitudes regarding participating in physical activity to continue social relations $(r=.19 ; p<.05)$ and to achieve catharsis $(r=.18 ; p$ $<.05)$ but was not related to any of the other five attitudinal subscales (see Table 3.9). 
Table 3.8 Correlations for Male Caregiver's Parenting Style and Adolescent Attitudes

\begin{tabular}{|c|c|c|c|c|c|c|c|c|c|c|c|}
\hline & $\begin{array}{c}\text { Male } \\
\text { Authoritative }\end{array}$ & $\begin{array}{c}\text { Male } \\
\text { Authoritarian }\end{array}$ & $\begin{array}{c}\text { Male } \\
\text { Permissive }\end{array}$ & $\begin{array}{c}\text { Male } \\
\text { Nurturance }\end{array}$ & $\begin{array}{l}\text { Social } \\
\text { Growth }\end{array}$ & $\begin{array}{l}\text { Social } \\
\text { Cont. }\end{array}$ & $\begin{array}{l}\text { Health } \\
\& \\
\text { Fitness }\end{array}$ & Vertigo & Aesthetic & Catharsis & Ascetic \\
\hline $\begin{array}{l}\text { Male } \\
\text { Authoritative }\end{array}$ & 1 & .01 & .13 & $.64 * *$ & .18 & $.25 * *$ & .13 & .03 & .11 & .13 & .00 \\
\hline $\begin{array}{l}\text { Male } \\
\text { Authoritarian }\end{array}$ & $-.28 * *$ & 1 & $-.38 * *$ & -.17 & -.03 & .06 & .06 & .07 & .09 & .12 & $.23 *$ \\
\hline $\begin{array}{l}\text { Male } \\
\text { Permissive }\end{array}$ & .17 & $-.44 * *$ & 1 & -.01 & .12 & .05 & .02 & -.11 & .18 & -.01 & -.01 \\
\hline $\begin{array}{l}\text { Male } \\
\text { Nurturance }\end{array}$ & $.77 * *$ & $-.29 * *$ & .13 & 1 & $.25 * *$ & $.21 *$ & $.22 *$ & .03 & .08 & -.01 & .02 \\
\hline $\begin{array}{l}\text { Social } \\
\text { Growth }\end{array}$ & -.08 & .02 & -.07 & .02 & 1 & $.61 * *$ & $.48 * *$ & .15 & $.34 *$ & $.37 * *$ & $.20 *$ \\
\hline $\begin{array}{l}\text { Social } \\
\text { Continuation }\end{array}$ & -.13 & .18 & -.11 & -.12 & $.42 * *$ & 1 & $.46 * *$ & .12 & $.35 * *$ & $.41 * *$ & .17 \\
\hline $\begin{array}{l}\text { Health \& } \\
\text { Fitness }\end{array}$ & .14 & .06 & .01 & .14 & $.45 * *$ & $.27 * *$ & 1 & .11 & $.36 * *$ & $.35 * *$ & $.34 * *$ \\
\hline Vertigo & .19 & .09 & -.01 & .15 & $.26 * *$ & -.02 & .11 & 1 & -.05 & $.27 * *$ & $.24 * *$ \\
\hline Aesthetic & .02 & .00 & .03 & -.02 & $.19 *$ & .09 & $.21 *$ & -.09 & 1 & $.27 * *$ & .13 \\
\hline Catharsis & .04 & .01 & .06 & -.06 & $.20^{*}$ & $.31 * *$ & $.35 * *$ & -.07 & $.26 * *$ & 1 & $.26 * *$ \\
\hline Ascetic & -.14 & .12 & .06 & -.08 & $.30 * *$ & -.01 & $.26 * *$ & $.35 * *$ & .11 & .07 & 1 \\
\hline
\end{tabular}

${ }^{*} p<.05 ;{ }^{*} p<.01$; All correlations above the diagonal line correspond to male participants and all correlations below the diagonal line correspond to female participants.

\section{Table 3.9 Correlations for Female Caregiver's Parenting Style and Adolescent Attitudes}

\begin{tabular}{|c|c|c|c|c|c|c|c|c|c|c|c|}
\hline & $\begin{array}{c}\text { Female } \\
\text { Authoritative }\end{array}$ & $\begin{array}{c}\text { Female } \\
\text { Authoritarian }\end{array}$ & $\begin{array}{c}\text { Female } \\
\text { Permissive }\end{array}$ & $\begin{array}{c}\text { Female } \\
\text { Nurturance }\end{array}$ & $\begin{array}{l}\text { Social } \\
\text { Growth }\end{array}$ & $\begin{array}{l}\text { Social } \\
\text { Cont. }\end{array}$ & $\begin{array}{l}\text { Health } \\
\& \\
\text { Fitness }\end{array}$ & Vertigo & Aesthetic & Catharsis & Ascetic \\
\hline $\begin{array}{l}\text { Female } \\
\text { Authoritative }\end{array}$ & 1 & -.01 & .04 & $.47 * *$ & .08 & $.21 *$ & .13 & .16 & .03 & $.25^{* *}$ & -.01 \\
\hline $\begin{array}{l}\text { Female } \\
\text { Authoritarian }\end{array}$ & $-.21^{*}$ & 1 & $-.45 * *$ & $-.21 *$ & .13 & .12 & .18 & .18 & .04 & .11 & .17 \\
\hline $\begin{array}{l}\text { Female } \\
\text { Permissive }\end{array}$ & $.20 *$ & $-.40 * *$ & 1 & -.01 & .06 & .04 & .04 & -.04 & .16 & .08 & .01 \\
\hline $\begin{array}{l}\text { Female } \\
\text { Nurturance }\end{array}$ & $.73 * *$ & $-.44 * *$ & .18 & 1 & .12 & $.27 * *$ & .13 & .01 & $.20 *$ & .01 & -.01 \\
\hline $\begin{array}{l}\text { Social } \\
\text { Growth }\end{array}$ & .06 & -.00 & .04 & .09 & 1 & $.61 * *$ & $.48 * *$ & .15 & $.34 *$ & $.37 * *$ & $.20 *$ \\
\hline $\begin{array}{l}\text { Social } \\
\text { Continuation }\end{array}$ & $.19 *$ & -.11 & .09 & $.30 * *$ & $.42 * *$ & 1 & $.46^{* *}$ & .12 & $.35^{* *}$ & $.41 * *$ & .17 \\
\hline $\begin{array}{l}\text { Health \& } \\
\text { Fitness }\end{array}$ & .14 & -.01 & .06 & $.19 *$ & $.45^{* *}$ & $.27 * *$ & 1 & .11 & $.36^{* *}$ & $.35^{* *}$ & $.34 * *$ \\
\hline Vertigo & -.03 & .06 & .03 & .02 & $.26^{* *}$ & -.02 & .11 & 1 & -.05 & $.27 * *$ & $.24 * *$ \\
\hline Aesthetic & .02 & -.06 & .06 & -.03 & $.19 *$ & .09 & $.21 *$ & -.09 & 1 & $.27 * *$ & .13 \\
\hline Catharsis & $.18^{*}$ & -.20 & .09 & .06 & $.20 *$ & $.31 * *$ & $.35^{* *}$ & -.07 & $.26 * *$ & 1 & $.26 * *$ \\
\hline Ascetic & -.14 & -.00 & .15 & -.07 & $.30 * *$ & -.01 & $.26 * *$ & $.35^{* *}$ & .11 & .07 & 1 \\
\hline
\end{tabular}

${ }^{*} p<.05 ;{ }^{* *} p<.01$; All correlations above the diagonal line correspond to male participants and all correlations below the diagonal line correspond to female participants. 
The fourth hypothesis was that intrinsic motivation and favorable attitudes toward physical activity would be positively related to physical activity participation in adolescents. For male participants, more favorable attitudes toward physical activity as a method to staying healthy and fit were positively related to strenuous physical activity $(r=.27 ; p<.01)$. Also, more favorable attitudes toward physical activity involving vertigo were positively related toward moderate $(r=.19 ; p<.05)$ and mild $(r=.20 ; p<.05)$ levels of physical activity (see Table 3.10). Additionally, more favorable attitudes toward physical activity as an ascetic activity (e.g., involving long and hard training) were positively related to strenuous physical activity $(r=$ $.29 ; p<.01)$ and moderate physical activity $(r=.20 ; p<.05)$ for male participants. Additionally for male participants, introjected $(r=.33 ; p<.01)$, identified $(r=.44 ; p<.01)$, and intrinsic $(r=$ $.45 ; p<.01$ ) regulation were positively related to strenuous physical activity (see Table 3.11 ). Identified regulation was also related to moderate physical activity $(\mathrm{r}=.21 ; \mathrm{p}<.05)$ and external regulation was positively related to mild physical activity $(r=.26 ; \mathrm{p}<.01)$. For female participants, more favorable attitudes toward physical activity for social growth were positively related to strenuous $(r=.19 ; p<.05)$ and mild physical activity participation $(r=.19 ; p<.05$; see Table 3.10). Also, more favorable attitudes toward physical activity as a method to stay healthy and fit were positively related to strenuous $(r=.24 ; p<.01)$ and moderate physical activity participation $(r=.22 ; p<.05)$. Additionally for female participants, introjected, identified, and intrinsic motivation were all related to different levels of physical activity participation (see Table 3.11). Introjected motivation was positively related to strenuous physical activity $(r=.49 ; p<.01)$, moderate physical activity $(r=.22 ; p<.05)$, and mild physical activity $(r=.21 ; p<.05)$. Identified motivation was positively related to strenuous physical activity $(r=.64 ; p<.01)$, moderate physical activity $(r=.42 ; p<.01)$, and mild 
physical activity $(r=.21 ; p<.05)$. Intrinsic motivation was positively related to strenuous physical activity $(r=.59 ; p<.01)$, moderate physical activity $(r=.49 ; p<.01)$ and mild physical activity $(r=.33 ; p<.01)$.

Table 3.10 Correlations for Adolescent Attitudes and Physical Activity Participation

\begin{tabular}{|c|c|c|c|c|c|c|c|c|c|c|}
\hline & $\begin{array}{l}\text { Social } \\
\text { Growth }\end{array}$ & $\begin{array}{l}\text { Social } \\
\text { Cont. }\end{array}$ & $\begin{array}{c}\text { Health \& } \\
\text { Fitness }\end{array}$ & Vertigo & Aesthetic & Catharsis & Ascetic & $\begin{array}{c}\text { Strenuous } \\
\text { Activity }\end{array}$ & $\begin{array}{c}\text { Moderate } \\
\text { Activity }\end{array}$ & $\begin{array}{c}\text { Mild } \\
\text { Activity }\end{array}$ \\
\hline $\begin{array}{l}\text { Social } \\
\text { Growth }\end{array}$ & 1 & $.61 * *$ & $.48 * *$ & .15 & $.34 *$ & $.37 * *$ & $.20^{*}$ & .09 & .15 & .10 \\
\hline $\begin{array}{l}\text { Social } \\
\text { Continuation }\end{array}$ & $.42 * *$ & 1 & $.46^{* *}$ & .12 & $.35 * *$ & $.41 * *$ & .17 & .16 & .16 & .07 \\
\hline $\begin{array}{l}\text { Health \& } \\
\text { Fitness }\end{array}$ & $.45 * *$ & $.27 * *$ & 1 & .11 & $.36 * *$ & $.35^{* *}$ & $.34 * *$ & $.27 * *$ & .15 & -.07 \\
\hline Vertigo & $.26 * *$ & -.02 & .11 & 1 & -.05 & $.27 * *$ & $.24 * *$ & .09 & $.19 *$ & $.20 *$ \\
\hline Aesthetic & $.19 *$ & .09 & $.21 *$ & -.09 & 1 & $.27 * *$ & .13 & .06 & -.04 & -.01 \\
\hline Catharsis & $.20^{*}$ & $.31 * *$ & $.35^{* *}$ & -.07 & $.26 * *$ & 1 & $.26 * *$ & .07 & .05 & .06 \\
\hline Ascetic & $.30 * *$ & -.01 & $.26^{* *}$ & $.35^{* *}$ & .11 & .07 & 1 & $.29 * *$ & $.20 *$ & .20 \\
\hline $\begin{array}{l}\text { Strenuous } \\
\text { Activity }\end{array}$ & $.19^{*}$ & .14 & $.24 * *$ & .10 & .08 & .12 & .17 & 1 & $.24 * *$ & -.02 \\
\hline $\begin{array}{l}\text { Moderate } \\
\text { Activity }\end{array}$ & .07 & -.07 & $.22 *$ & .13 & .17 & -.01 & -.07 & $.43 * *$ & 1 & $.39 * *$ \\
\hline $\begin{array}{l}\text { Mild } \\
\text { Activity }\end{array}$ & $.19 *$ & .07 & .13 & .06 & .16 & .07 & .01 & $.25^{* *}$ & $.40 * *$ & 1 \\
\hline
\end{tabular}

${ }^{*} p<.05 ; *^{*} p<.01$; All correlations above the diagonal line correspond to male participants and all correlations below the diagonal line correspond to female participants.

\section{Table 3.11 Correlations for Adolescent Motivation and Physical Activity Participation}

\begin{tabular}{|c|c|c|c|c|c|c|c|c|}
\hline Amotivation & $\begin{array}{c}\text { Amotivation } \\
1\end{array}$ & $\begin{array}{l}\text { External } \\
\text { Regulation } \\
.27 * *\end{array}$ & $\begin{array}{l}\text { Introjected } \\
\text { Regulation } \\
-.23^{*}\end{array}$ & $\begin{array}{l}\text { Identified } \\
\text { Regulation } \\
-.42 * *\end{array}$ & $\begin{array}{l}\text { Intrinsic } \\
\text { Regulation } \\
-.50^{* *}\end{array}$ & $\begin{array}{c}\text { Strenuous } \\
\text { Activity } \\
-.29 * *\end{array}$ & $\begin{array}{c}\text { Moderate } \\
\text { Activity } \\
-.17\end{array}$ & $\begin{array}{c}\text { Mild } \\
\text { Activity } \\
.08\end{array}$ \\
\hline $\begin{array}{l}\text { External } \\
\text { Regulation }\end{array}$ & $.24 * *$ & 1 & $.23 * *$ & .10 & -.03 & .08 & -.02 & $.26 * *$ \\
\hline $\begin{array}{l}\text { Introjected } \\
\text { Regulation }\end{array}$ & -.18 & .13 & 1 & $.60 * *$ & $.45^{* *}$ & $.33 * *$ & .16 & .10 \\
\hline $\begin{array}{l}\text { Identified } \\
\text { Regulation }\end{array}$ & $-.46 * *$ & -.08 & $.63 * *$ & 1 & $.73 * *$ & $.44 * *$ & $.21 *$ & -.05 \\
\hline $\begin{array}{l}\text { Intrinsic } \\
\text { Regulation }\end{array}$ & $-.48 * *$ & $-.28 * *$ & $.44 * *$ & $.79 * *$ & 1 & $.45^{* *}$ & .13 & -.08 \\
\hline $\begin{array}{l}\text { Strenuous } \\
\text { Activity }\end{array}$ & $-.26 * *$ & -.01 & $.49 * *$ & $.64 * *$ & $.59 * *$ & 1 & $.24 * *$ & -.02 \\
\hline $\begin{array}{l}\text { Moderate } \\
\text { Activity }\end{array}$ & -.15 & -.06 & $.22 *$ & $.42 * *$ & $.49 * *$ & $.43 * *$ & 1 & $.39 * *$ \\
\hline $\begin{array}{l}\text { Mild } \\
\text { Activity }\end{array}$ & -.14 & -.15 & $.21 *$ & $.21^{*}$ & $.33 * *$ & $.25^{* *}$ & $.40 * *$ & 1 \\
\hline
\end{tabular}

${ }^{*} p<.05 ; *^{*} p<.01$; All correlations above the diagonal line correspond to male participants and all correlations below the diagonal line correspond to female participants. 
The fifth hypothesis was that there would be differences between males and females on their assessment of parenting style, motivation, and attitudes. MANOVA analyses were used to assess difference in the independent variable of males or females on the dependent variables of parenting style, motivation, and attitudes. Males and females did indeed differ on their assessment of their male caregiver's permissive parenting style. Male participants $(M=26.58$, $S D=5.59$ ) rated their male caregivers as significantly more permissive than female participants $\left(M=24.96, S D=5.99 ; F(1,223), p=.038, \eta^{2}=.019 ;\right.$ see Table 3.12). Males and females also differed on their assessment of their female caregiver's permissive parenting style. Again, male participants $(M=27.34, S D=5.48)$ rated their female caregivers as significantly more permissive than female participants $\left(M=25.59, S D=5.93 ; F(1,238), p=.018, \eta^{2}=.023\right)$.

Males and females also differed on their assessment of attitudes regarding physical activity. Males $(M=3.25 ; S D=5.33)$ rated physical activity that involves vertigo more favorably than did females $\left(M=-1.13 ; S D=4.61 ; F(1,224), p<.001, \eta^{2}=.162\right.$; see Table 3.12). Females $(M=5.57 ; S D=4.34)$ rated physical activity that has aesthetic qualities more favorably than did males $\left(M=1.51 ; S D=5.78 ; F(1,224), p<.001, \eta^{2}=.136\right)$. Females $(M=$ 8.15; $S D=2.38$ ) also rated physical activity involving catharsis more favorably than did males $\left(M=6.75 ; S D=3.53 ; F(1,224), p=.001, \eta^{2}=.050\right)$. Males $(M=2.83 ; S D=5.07)$ rated physical activity with ascetic qualities more favorably than females $(M=-.11 ; S D=4.94 ; F(1$, 224), $\left.p<.001, \eta^{2}=.080\right)$. A final difference between males and females was on their assessment of intrinsic motivation. Males $(M=12.02 ; S D=3.79)$ rated their levels of intrinsic regulation significantly higher than females $\left(M=9.92 ; S D=4.52 ; F(1,242), p<.001, \eta^{2}=\right.$ .061 ; see Table 3.12). 
Table 3.12 Means and Standard Deviation for All Research Variables

\begin{tabular}{lcccc} 
& \multicolumn{2}{c}{ Males } & \multicolumn{2}{c}{ Females } \\
Male Authoritative & Mean & $\underline{\text { S.D. }}$ & $\underline{\text { Mean }}$ & $\underline{\text { S.D. }}$ \\
Male Authoritarian & 33.38 & 5.90 & 35.09 & 8.59 \\
Male Permissive & 26.58 & 5.60 & 33.14 & 8.40 \\
Male Nurturance & 93.92 & 18.42 & 24.96 & 6.00 \\
Female Authoritative & 35.05 & 5.54 & 36.32 & 23.95 \\
Female Authoritarian & 32.79 & 6.48 & 32.33 & 7.28 \\
Female Permissive & 27.34 & 5.48 & 25.59 & 5.05 \\
Female Nurturance & 98.41 & 15.28 & 99.25 & 21.39 \\
Social Growth & 5.53 & 3.30 & 6.08 & 3.44 \\
Social Continuation & 7.53 & 2.91 & 7.73 & 3.20 \\
Health \& Fitness & 7.56 & 2.72 & 7.35 & 3.06 \\
Vertigo & 3.25 & 5.33 & -1.13 & 4.61 \\
Aesthetic & 1.51 & 5.78 & 5.57 & 4.34 \\
Catharsis & 6.75 & 3.53 & 8.15 & 2.38 \\
Ascetic & 2.83 & 5.07 & -0.11 & 4.94 \\
Amotivation & 1.40 & 2.18 & 1.93 & 3.28 \\
External & 3.58 & 3.46 & 3.68 & 3.31 \\
Introjected & 5.08 & 3.36 & 4.98 & 3.47 \\
Identified & 11.39 & 3.41 & 10.48 & 3.97 \\
Intrinsic & 12.02 & 3.79 & 9.92 & 4.52 \\
Strenuous PA & 4.08 & 1.88 & 3.20 & 2.17 \\
Moderate PA & 3.59 & 2.45 & 3.91 & 2.10 \\
Mild PA & 3.58 & 2.61 & 3.73 & 2.61
\end{tabular}

The sixth hypothesis was that there would be differences between racial and ethnic groups on their assessment of parenting styles. This hypothesis was not able to be tested due to the lack an adequate sample of racially and ethnically diverse participants. Over $91 \%$ of the sample fell into two racial categories and comparisons between groups who had only one or two participants in them were not able to be computed.

The seventh hypothesis was that there would be differences in the amount of variance each of the predictor variables have on the criterion variable of physical activity participation. For this hypothesis, only the predictor variables that were significantly correlated with either strenuous, moderate, or mild physical activity participation were included. Multi-collinearity was also examined and was not deemed to be problematic as predictor variables were examined 
in a correlation matrix to ensure that the variables were not correlated with each other. The variables were also examined so that tolerance levels were greater than .20 and VIF levels were less than 2.0. Six stepwise regression analyses were run to examine the amount of variance predictor variables accounted for regarding the criterion variables of strenuous, moderate, and mild physical activity participation. Regressions were conducted separately for males and females for each level of physical activity participation (e.g., males-strenuous, males-moderate, males-mild, females-strenuous, females-moderate, and females-mild).

The first regression examined the permissive parenting style from the male caregiver, attitudes regarding physical activity as a method to staying healthy and fit, attitudes regarding physical activity as containing ascetic characteristics, and introjected, identified, and intrinsic regulation in predicting males' strenuous physical activity participation. One statistically significant model emerged from this regression analysis $\left(F(1,107)=26.91, p<.001, R^{2}=.193\right)$. This model found that identified regulation significantly predicted strenuous physical activity participation in males $(B=.448, p<.001)$. This regression indicates that for male participants, identified regulation accounts for about $19 \%$ of the variance in strenuous physical activity participation.

The second regression analysis included the predictor variables of a permissive parenting style from the male caregiver, a permissive parenting style from the female caregiver, nurturance from the female caregiver, attitudes regarding physical activity as containing ascetic characteristics, attitudes regarding physical activity involving vertigo, and identified regulation and the criterion variable of males' moderate physical activity participation. Two statistically significant models were generated and the second model was retained $(F(2,99)=4.33, p=.016$, $\left.R^{2}=.062\right)$. This second model was retained because it was more parsimonious than the first. 
While the first model accounted for one variable and about $3 \%$ of the variance, the second model included two variables and accounted for twice as much variance than the first model. This is the model of choice due to the variance being doubled and each variable accounting for about $3 \%$ of the variance. This model indicated that both identified regulation $(B=.200, p=.040)$ and a permissive parenting style from the male caregiver $(B=.195, p=.046)$ were significant predictor variables on moderate physical activity participation in male participants. This indicates that for male participants, identified regulation and a permissive parenting style from the male caregiver account for about $6 \%$ of the variance in moderate physical activity participation.

The third regression analysis included the predictor variables of attitudes regarding physical activity involving vertigo and external regulation and the criterion variable of males' mild physical activity participation. One statistically significant model was generated and retained from this regression analysis $\left(F(1,119)=8.909, p=.003, R^{2}=.062\right)$. This model indicated that the variable of external regulation was a significant predictor variable on males' mild physical activity participation $(B=.264, p=.003)$. This indicates that for male participants, external regulation accounts for about $6 \%$ of the variance in mild physical activity participation.

The fourth regression analysis included the predictor variables of attitudes regarding physical activity as a means of social growth, attitudes regarding physical activity as a method to stay healthy and fit, introjected, identified, and intrinsic motivation and the criterion variable of females' strenuous physical activity participation. Three statistically significant models were generated and the first model was retained from this regression analysis $(F(1,115)=83.304, p<$ $\left..001, R^{2}=.415\right)$. This model indicates that the variable of identified regulation $(B=.648, p<$ .001 ) is a significant predictor of strenuous physical activity participation for females. This 
model was chosen because it is the most parsimonious in that it included only one variable, but this variable alone account for about $42 \%$ of the variance. The other two models each added an additional variable but only about one percent increase in the variance. The second model also included the variable of introjected regulation but only increased the variance to about $44 \%$ and the third model added the variable of intrinsic regulation but only increased the variance accounted for to about $45 \%$. It is clear that identified regulation is providing the largest amount of variance and so the first model was retained for interpretation.

The fifth regression included the predictor variables of an authoritative parenting style from the male caregiver, nurturance from the male caregiver, an authoritative parenting style from the female caregiver, attitudes regarding physical activity as a method for staying healthy and fit, and introjected, identified, and intrinsic regulation on the criterion variable of females' moderate physical activity participation. Two statistically significant models were generated and the second model was retained for interpretation $\left(F(2,106)=26.595, p<.001, R^{2}=.322\right)$. This model included two predictor variables: intrinsic regulation $(B=.479, p<.001)$ and nurturance from the male caregiver $(B=.313, p<.001)$. This model was chosen because it was parsimonious in that there were two variables included and the second variable added about $10 \%$ of the variance. Intrinsic motivation accounted for approximately $23 \%$ of the variance and nurturance from the male caregiver accounted for approximately $9 \%$ of the variance. This indicates that for female participants, intrinsic regulation and nurturance from the male caregiver account for about $32 \%$ of the variance in moderate physical activity participation.

The sixth regression analysis included the predictor variables of an authoritative parenting style from the male caregiver, an authoritative parenting style from the female caregiver, attitudes regarding physical activity participation as a means for social growth, and 
introjected, identified, and intrinsic regulation on the criterion variable of females' mild physical activity participation. One statistically significant model was generated from this regression analysis $\left(F(1,107)=12.142, p=.001, R^{2}=.094\right)$. This model includes the variable of intrinsic regulation $(B=.319, p=.001)$ and indicates that intrinsic regulation accounts for approximately $9 \%$ of the variance in females' mild physical activity participation.

\section{Discussion}

The purpose of the present study was to examine the relationship that many variables had on adolescents' level of physical activity participation. These variables included the adolescents' perceptions of their caregivers' parenting styles, adolescents' attitudes regarding physical activity, and adolescents' motivation levels regarding physical activity. Because many gender differences emerged, the following section will also be organized and discussed separately for each gender.

\section{Male Adolescents}

An initial point of discussion is the emergence of the permissive parenting style as influencing male participants' physical activity participation. This was in contrast to the research hypothesis that predicted that an authoritative parenting style would be positively related to physical activity, thus this hypothesis was not supported. Previous research lent support to the benefits of an authoritative parenting style for various behaviors such as lowering problem drug use and lowering risk factors in adolescents (Baumrind, 1991; Newman, Harrison, Dashiff, \& Davies, 2008). However, the one prior study that has specifically looked at parenting style and physical activity participation did not find any significant associations between parenting style and adolescent physical activity participation (Berge, Wall, Loth, \& Neumark-Sztainer, 2010). This study provides a novel finding in that there was a significant relationship between a 
permissive parenting style from both the male and female caregiver and adolescent male physical activity participation. A permissive parenting style might be influencing adolescents to partake in more physical activity because they are still receiving support and high levels of responsiveness from their caregivers but they do not feel pressure from high demands placed on them. In present society, adolescents are becoming more independent, suggesting that if they receive adequate support and responsiveness from their caregivers, they do not need the high levels of demands and expectations to be motivated to be physically active. Caregivers might be more likely to be more permissive with males than females because of social and gender roles that often promote males as the more independent gender (Cole, Cole, \& Lightfoot, 2005). High levels of nurturance from the female caregiver were also related to moderate levels of physical activity for males. This cross-gender relationship where the caregiver provides high levels of support and nurturance to the child is a pertinent finding and contributes to the benefits of support for adolescents in regards to their physical activity participation.

An authoritative parenting style was also not related to high levels of self-determined motivation for males. This was again, contrary to what the research hypothesis predicted. However, an authoritative parenting style from both the male and female caregiver was related to more favorable attitudes toward physical activity in the areas of social growth and achieving catharsis, or a release of tension while being active. This supports the research hypothesis predicting a positive association between an authoritative parenting style and more favorable attitudes toward physical activity.

Male participants differed from females in their assessment of parenting style, attitudes toward physical activity, and motivation, thus supporting the research hypothesis predicting these differences. Male participants indicated that their attitudes toward physical activity 
centered on being healthy and fit, achieving vertigo or an element of risk, and having ascetic properties or involving long and hard training. This indicates that males enjoy physical activity that might be more challenging and also involve more risk, but they value these activities because of the benefits of being healthy and fit. Developmentally, this fits in with adolescents' perceptions of their world as being self-centered and their desire to look good among their peers (Cole et al., 2005). Male participants also rated their intrinsic motivation as higher which might suggest that adolescents would need to be more intrinsically motivated to participate in more strenuous forms of physical activity. Adolescents might partake in mild or moderate physical activity when motivated by extrinsic forms of motivation but high amounts of strenuous activity might need more intrinsic motivation for adolescents to adhere to physical activity and enjoy it. This assumption is also supported by the results of the regression analyses. Strenuous physical activity for males is predicted by identified regulation, and moderate physical activity is also predicted by identified regulation and a permissive parenting style from the male caregiver. This level of regulation involves appreciation of the outcomes of behavior, which indicates a higher level of intrinsic motivation than external or introjected motivation. The permissive parenting style is again a common factor in promoting a moderate level of physical activity. However, at lower levels of physical activity, males were motivated by more external factors, which is consistent with the assumption that adolescents will participate in milder forms of physical activity when motivated by external factors but need higher levels of intrinsic motivation to participate in more strenuous activities (Gillison, Standage, \& Skevington, 2006; Spray, JohnWang, Biddle, \& Chatzisarantis, 2006).

Overall, male adolescents seem to benefit from a permissive parenting style due to the high levels of support and responsiveness involved. An authoritative parenting style was 
beneficial though in relation to favorable attitudes toward physical activity. The common factor in the results for males seems to be the high level of responsiveness and support that is a characteristic of both authoritative and permissive parenting styles. Males seem to enjoy physical activity more when they view physical activity as a method to be healthy and fit, involving long and hard training, and when it involves an element of risk. Due to the socially derived gender roles for males, these findings make sense as males are typically seen as more adventurous, independent, and have high physical activity ability (Elkind, 1994). Males also seem to be motivated by more internal feelings when they participate in strenuous physical activity but can be motivated by more external factors when they are participating in lower levels of physical activity. Individuals may need motivation to participate in difficult tasks and previous research has demonstrated that motivation that is closer to intrinsic and self-determined is more likely to motivate us to engage in harder tasks (Biddle, 1999). Easier tasks, such as mild or moderate physical activity, might be motivated by more external aspects, such as pleasing others or getting an external reward. However, the results from males about higher levels of motivation being associated with more strenuous activity is consistent with previous research that more self-determined motivation is associated with participating and maintaining positive behaviors, such as physical activity (Biddle, 1999; Chatzisarantis et al., 1997; Gillison et al., 2006; Spray et al., 2006).

\section{Female Adolescents}

Female adolescents in this study demonstrated different perceptions and behaviors than males, as was hypothesized. While the permissive parenting style surfaced as being relevant for males, females seem to benefit from an authoritative parenting style from both the male and female caregiver in terms of physical activity participation. This provides support for the 
research hypothesis predicting a positive relationship between an authoritative parenting style and adolescent physical activity participation. However, this hypothesis is only partially supported since this finding was not true for males. This relationship between an authoritative parenting style and physical activity indicates that adolescent females may benefit from high levels of demands and expectations as well as high levels of support and responsiveness when examining physical activity behaviors. This is coupled with the finding that nurturance from the male caregiver also was associated with moderate and mild levels of physical activity for females. Once again, a cross-gender dyad is present where high levels of nurturance from the opposite-sex caregiver seem to boost moderate physical activity levels. Culturally and socially, females might be held to different and/or higher standards than males since they are seen as more nurturing and less self-directed than males (Eklund, 1994). This gender-role bias may be evidenced through the authoritative parenting style being associated to physical activity for females but not for males.

An authoritative parenting style from the female-care giver was also associated with favorable attitudes toward physical activity. This supports the hypothesis that an authoritative parenting style would be associated with more favorable attitudes. These attitudes differed from males however. Overall, females had more favorable attitudes toward physical activity for social reasons, to achieve catharsis (release tension), and as a method for staying healthy and fit. The attitudes toward physical activity for social growth and as a method for staying healthy and fit were then related to strenuous levels of physical activity participation. The attitudes regarding physical activity as a means to stay healthy and fit is a similarity between males and females, but the social aspect of physical activity is unique to females. This is not unexpected given what is known about adolescent females and their developmental nature to be social and consider their 
social life a high priority (Cole et al., 2005; Eklund, 1994). Also unlike males, female adolescents had a unique relationship with their authoritative female caregiver in that this parenting style was related to introjected, identified, and intrinsic motivation. This finding provides partial support for the hypothesis that an authoritative parenting style would be related to intrinsic motivation in adolescents. This finding also provides more evidence for the benefits of an authoritative parenting style for females but not for males. Previous research has also found benefits of an authoritative parenting style on health-related behaviors specifically for female adolescents. For example, Berge, Wall, Loth, and Neumark-Sztainer (2010) found that an authoritative parenting style from the maternal caregiver was related to a lower BMI (bodymass index) for females. The present study supports this line of research on the importance of an authoritative parenting style for the adolescent female in regards to health-related behaviors.

Although females differed from males in regards to parenting style, attitudes, and motivational levels, females were similar to males in that motivation was a significant predictor of physical activity participation. Intrinsic motivation was a predictor for both moderate and mild physical activity participation and nurturance from the male caregiver was also a predicting variable in moderate physical activity participation. Similar to males, strenuous physical activity participation in females was predicted by identified regulation more so than introjected or intrinsic regulation. This may indicate a level of regulation that is particularly common amongst adolescents regardless of gender.

The present study adds several novel findings to the area of research on parenting style and adolescent physical activity participation, attitudes, and motivation. Because no significant findings have been previously published regarding parenting style and physical activity, the present study provides initial support toward a significant parenting style for each gender. The 
present study also provides novel findings regarding factors related to physical activity and how these factors are related to both parenting style and predicting physical activity participation among adolescents. While the authoritative parenting style was not positively associated with physical activity, more favorable attitudes, and intrinsic motivation for both genders, this study provides evidence for the need to research this area further to see how family dynamics and psychosocial variables are interacting to promote or inhibit physical activity participation.

\section{Limitations}

As mentioned before, limitations of the present study include issues with the methodology. Participants provided self-report data for all of the measures, which can potentially lead to participants giving socially desirable answers instead of an accurate assessment of their perceptions. Another limitation is that physical activity was assessed through a pencil-and-paper method rather than by a more detailed objective or physiological method where there is limited potential for participants to be dishonest about their levels of activity. Additionally, because the measure of physical activity was geared toward leisure-time activities, we are unaware if participants included their occupational, household, or transportation physical activity in their daily totals. Other limitations include issues with the sample utilized in the present study. The sample was a convenience sample and was comprised of only high school students, making it difficult to generalize results to other age groups. Also, this particular sample lacked diversity in terms of race and ethnicity and made it impossible to compare results between certain ethnic and racial groups due to a lack of variety in the sample.

\section{Implications}

The results from this study provide information on how adolescents perceive their relationships with their caregivers as well as how these relationships combined with their 
attitudes and motivation contribute to their physical activity participation. These findings can be helpful in providing education to parents of adolescents and what characteristics of their parenting style can be helping or hindering the development of health behaviors in their children. Parents or caregivers can benefit from knowing how their child perceives their parenting style and can possibly modify their individual parenting style to fit circumstances as needed. The results from this study also help educators and professionals to understand why adolescents participate in physical activity and how these attitudes and reasons differ for each gender. If caregivers, educators, and helping professionals can incorporate the attitudes associated with physical activity participation as well as provide appropriate motivation for an adolescent, participation in healthy behaviors might not only increase but be maintained in adolescence and throughout their lives. These healthy behaviors can reduce the risk of health problems and can benefit individuals in both their physical and mental aspects of their lives.

An additional implication is the suggestion of a proactive approach to promoting physical activity and preventing childhood obesity. It seems that much of the previous research focuses on how to alleviate or reduce problems after they have occurred rather than preventing them from becoming a problem completely. The results from the present study suggest that fostering nurturance from the caregiver to the opposite-sex child and providing support in either a permissive or authoritative parenting style should begin before adolescence so that children will have incorporated physical activity into their lifestyle and are already maintaining healthy behaviors. This is in contrast to the idea of promoting a lifestyle change either in adolescence or later on in life. The issue in question is whether interventions should focus on reducing negative behaviors after they happen (a reactive approach) or promoting positive behaviors in the hopes that negative behaviors will never occur (a proactive approach). The results from the present 
study appear to support the benefits of a proactive approach regarding interventions. By promoting the appropriate parenting styles, attitudes, and motivation early on, the need to find ways to intervene and promote positive health behaviors in adolescence or adulthood might be reduced since these behaviors would already be fostered and incorporated into our daily lifestyle.

\section{Directions for Future Research}

Future research can further examine the relationship between caregivers and their children and the effects that these relationships have on the development of health behaviors in adolescents. Specifically, examining these relationships with culturally diverse samples to see how results and relationships might vary depending on racial and ethnic differences. Many of the results from this study seem to be related to socially or culturally defined gender roles, but since the sample was primarily White American adolescents, it would be important to see how the results would change with a different sample.

An additional area for future research might be the cross-gender relationship between the caregiver and the adolescent. At the developmental level of adolescence, fostering these crossgender relationships might be a vital area to investigate to benefit the development of health behaviors in adolescence and beyond. Examining the dynamics of these relationships can lead to more detailed information about what characteristics are the most beneficial in these relationships to develop more favorable attitudes toward physical activity, higher levels of selfdetermined motivation, and parenting styles that provide appropriate levels of expectations, support, and nurturance as required by the gender and developmental level of the child.

A final area for future research might be the adaptation of parenting style for caregivers. In other words, can parenting style be adapted or modified even after years of practicing a style? Adolescence is a difficult time for both the child and the caregiver and communication between 
these two generations is vital for the success of the relationship. If caregivers can become educated on what their parenting style is being perceived as from their child, then they can possibly modify or adapt their style to better promote what qualities might be lacking in the relationship. Realizing what factors contribute to successful physical activity participation in adolescence can help to promote these healthy behaviors as well as favorable attitudes and motivation to help adolescents form life-long behavioral habits. 


\section{References}

American College of Sports Medicine. (2006, April 12). Lessons in youth activity: Expert dispels misconceptions to motivate adults who influence children. Retrieved from http://www. acsm.org/AM/Template.cfm?Section=ACSM_News_Releases\&CONTENTID=5364\&T EMPLATE=/CM/ContentDisplay.cfm.

American College of Sports Medicine. (2007). Physical activity and public health guidelines. Retrieved from http://www.acsm.org/AM/Template.cfm?Section=Home_Page \& TEMPLATE=/CM/HTMLDisplay.cfm\&CONTENTID=7764.

Baumrind, D. (1966). Effects of authoritative parental control on child behavior. Child Development, 37, 887-907.

Baumrind, D. (1971). Current patterns of parental authority. Developmental Psychology, Monographs, 4, 1-103.

Baumrind, D. (1991). The influence of parenting style on adolescent competence and substance use. Journal of Early Adolescence, 11, 56-95.

Berge, J.M., Wall, M., Loth, K., \& Neumark-Sztainer, D. (2010). Parenting style as a predictor of adolescent weight and weight-related behaviors. Journal of Adolescent Health, 46, 331-338.

Biddle, S.J. (1999). Motivation and perceptions of control: Tracing its development and plotting its future in exercise and sport psychology. Journal of Sport and Exercise Psychology, $21,1-23$.

Brustad, R.J. \& Partridge, J.A. (2002). Parental and peer influence on children's psychosocial development through sport. In F.L. Smoll \& R.E. Smith (Eds.), Children and Youth in 
Sport: A Biopsychosocial Perspective (2 ${ }^{\text {nd }}$ ed.) (pp. 187-??). Dubuque, Iowa:

Kendall/Hunt Publishing Company.

Buri, J.R. (1989). Self-esteem and appraisals of parental behavior. Journal of Adolescent Research, 4, 33-49.

Buri, J.R. (1991). Parental authority questionnaire. Journal of Personality Assessment, 57, 110119.

Buri, J.R. \& Murphy, P. (1992). Stability of parental nurturance as a salient predictor of selfesteem. Psychological Reports, 71, 535-543.

Center for Disease Control and Prevention (CDC). (2010). Childhood overweight and obesity. Retrieved from http://www.cdc.gov/obesity/childhood/index.html.

Chatzisarantis, N.L.D., Biddle, S.J.H., \& Meek, G.A. (1997). A self-determination theory approach to the study of intentions and the intention-behavior relationship in children's physical activity. British Journal of Health Psychology, 2, 343-360.

Cole, M., Cole, S.R., \& Lightfoot, C. (2005). The development of children $\left(5^{\text {th }}\right.$ ed.). New York, NY: Worth Publishers.

Darling, N. \& Steinberg, L. (1993). Parenting style as context: An integrative model. Psychological Bulletin, 113, 487-496.

Deci, E.L., \& Ryan, R.M. (1985). Intrinsic motivation and self-determination in human behavior. New York: Plenum Press.

Elkind, D. (1994) A sympathetic understand of the child: Birth to sixteen ( $3^{\text {rd }}$ ed.). Needham Heights, MA: Allyn and Bacon.

Gillison, F.B., Standage, M., \& Skevington, S.M. (2006). Relationships among adolescents' weight perceptions, exercise goals, exercise motivation, quality of life and leisure-time 
exercise behavior: A self-determination theory approach. Health Education Research, 21, $836-847$.

Godin, G. \& Shephard, R.J. (1985). A simple method to assess exercise behavior in the community. Canadian Journal of Applied Sport Sciences, 10, 141-146.

Godin, G. \& Shephard, R.J. (1986). Importance of type of attitude to the study of exercisebehavior. Psychological Reports, 58, 991-1000.

Gustafson, S.L. \& Rhodes, R.E. (2006). Parental correlates of physical activity in children and early adolescents. Sports Medicine, 36, 79-97.

Kohl, H.W. \& Hobbs, K.E. (1998). Development of physical activity behaviors among children and adolescents. Pediatrics, 101, 549-554.

Loprinzi, P.D. \& Trost, S.G. (2010). Parental influences on physical activity behavior in preschool children. Preventive Medicine, 50, 129-133.

Markland, D. \& Tobin, V. (2004). A modification to the behavioral regulation in exercise questionnaire to include an assessment of amotivation. Journal of Sport and Exercise Psychology, 26, 191-196.

Mullan, E., Markland, D., \& Ingledew, D.K. (1997). A graded conceptualization of selfdetermination in the regulation of exercise behavior: Development of a measure using confirmatory factor analytic procedures. Personality and Individual Differences, 23, 745-752.

Newman, K., Harrison, L., Dashiff, C., \& Davies, S. (2008). Relationships between parenting styles and risk behaviors in adolescent health: An integrative literature review. Revista Latino-americana de Enfermagem, 16, 142-150. 
Pugliese, J. \& Tinsley, B. (2007). Parental socialization of child and adolescent physical activity: A meta-analysis. Journal of Family Psychology, 21, 331-343.

Sallis, J.F., Buono, M.J., Roby, J.J., Micale, F.G., \& Nelson, J.A. (1993). Seven-day recall and other physical activity self-reports in children and adolescents. Medicine and Science in Sports and Exercise, 25, 99-108.

Schutz, R.W., Smoll, F.L., Carre, F.A., \& Mosher, R.E. (1985). Inventories and norms for children's attitudes toward physical activity. Research Quarterly for Exercise and Sport, $56,256-265$.

Schutz, R.W., Smoll, F.L., Wood, T.M. (1981). A psychometric analysis of an inventory for assessing children's attitudes toward physical activity. Journal of Sport Psychology, 4, $321-344$.

Sirard, J.R. \& Pate, R.R. (2001). Physical activity assessment in children and adolescents. Journal of Sports Medicine, 31, 439-454.

Smoll, F.L. \& Schutz, R.W. (1980). Children's attitudes toward physical activity: A longitudinal analysis. Journal of Sport Psychology, 2, 137-147.

Spray, C.M, John-Wang, C.K., Biddle, S.J.H., \& Chatzisarantis, N.L.D. (2006). Understanding motivation in sport: An experimental test of achievement goal and self determination theories. European Journal of Sport Science, 6, 43-51.

Van Der Horst, K., Paw, M.J., Twisk, J.W., \& Van Mechelen, W. (2007). A brief review on correlates of physical activity and sedentariness in youth. Medicine and Science in Sports and Exercise, 39, 1241-1250.

Weiss, M.R. \& Williams, L. (2004). The why of youth sport involvement: A developmental perspective on motivational processes. In M.R. Weiss (Ed.), Developmental sport and 
exercise psychology: A lifespan perspective (pp. 223-268). Morgantown, WV: Fitness Information Technology, Inc. 


\section{Appendix A - Parental Authority Questionnaire (PAQ) and Parental Nurturance Scale (PNS) Pertaining to Female Care-Givers}

Instructions: For each of the following statements, use the 5-point scale $(1=$ strongly disagree, 5 = strongly agree) provided to indicate the number that best describes how that statement applies to you and your female care giver. Write the number on the line provided. Try to read and think about each statement as it applies to you and the relationship you currently have with your female care giver. There are no right or wrong answers, so don't spend a lot of time on any one item. We are looking for your overall impression regarding each statement. Be sure not to omit any items.

First, please indicate who you will be thinking about as you complete this questionnaire. Please think about a female who you consider to be the most important/primary care-giver in your life.
My Mother
My Grandmother
My Aunt

My Step-Mother

Other:(please write the relationship on the line provided)

1

Strongly

Disagree
2

Disagree
3

Neither disagree

nor agree
4

Agree Strongly Agree

1. While I was growing up my female care-giver felt that in a well-run home the children should have their way in the family as often as the care-givers do.

2. Even if her children didn't agree with her, my female care-giver felt that it was for our own good if we were forced to conform to what she thought was right.

3. Whenever my female care-giver told me to do something as I was growing up, she expected me to do it immediately without asking any questions.

4. As I was growing up, once family policy had been established, my female care-giver discussed the reasoning behind the policy with the children in the family.

5. My female care-giver has always encouraged verbal give-and-take whenever I have felt that family rules and restrictions were unreasonable.

6. My female care-giver has always felt that what children need is to be free to make up their own minds and to do what they want to do, even if this does not agree with what the care-givers might want. 
7. As I was growing up my female care-giver did not allow me to question any decision she had made.

8. As I was growing up my female care-giver directed the activities and decisions of the children in the family through reasoning and discipline.

9. My female care-giver has always felt that more force should be used by care-givers in order to get their children to behave the way they are supposed to.

10. As I was growing up my female care-giver did not feel that I needed to obey rules and regulations of behavior simply because someone in authority had established them.

11. As I was growing up I knew what my female care-giver expected of me in my family, but I also felt free to discuss those expectations with my female care-giver when I felt that they were unreasonable.

12. My female care-giver felt that wise care-givers should teach their children early just who is boss in the family.

13. As I was growing up, my female care-giver seldom gave me expectations and guidelines for my behavior.

14. Most of the time as I was growing up my female care-giver did what the children in the family wanted when making family decisions.

15. As the children in my family were growing up, my female care-giver consistently gave us direction and guidance in rational and objective ways.

16. As I was growing up my female care-giver would get very upset if I tried to disagree with her.

17. My female care-giver feels that most problems in society would be solved if caregivers would not restrict their children's activities, decisions, and desires as they are growing up.

18. As I was growing up my female care-giver let me know what behavior she expected of me, and if I didn't meet those expectations, she punished me.

19. As I was growing up my female care-giver allowed me to decide most things for myself without a lot of direction from her.

20. As I was growing up my female care-giver took the children's opinions into consideration when making family decisions, but she would not decide for something simply because the children wanted it. 
21. My female care-giver did not view herself as responsible for directing and guiding my behavior as I was growing up.

22. My female care-giver had clear standards of behavior for the children in our home as I was growing up, but she was willing to adjust those standards to the needs of each of the individual children in the family.

23. My female care-giver gave me direction for my behavior and activities as I was growing up and she expected me to follow her direction, but she was always willing to listen to my concerns and to discuss that direction with me.

24. As I was growing up my female care-giver allowed me to form my own point of view on family matters and she generally allowed me to decide for myself what I was going to do.

25. My female care-giver has always felt that most problems in society would be solved if we could get care-givers to strictly and forcibly deal with their children when they don't do what they are supposed to do as they are growing up.

26. As I was growing up my female care-giver often told me exactly what she wanted me to do and how she expected me to do it.

27. As I was growing up my female care-giver gave me clear direction for my behaviors and activities, but she was also understanding when I disagreed with her.

28. As I was growing up my female care-giver did not direct the behaviors, activities, and desires of the children in the family.

29. As I was growing up I knew what my female care-giver expected of me in the family and she insisted that I conform to those expectations simply out of respect for her authority.

30. As I was growing up, if my female care-giver made a decision in the family that hurt me, she was willing to discuss that decision with me and to admit it if she had made a mistake.

31. My female care-giver seldom says nice things about me.

32. I am an important person in my female care-giver's eyes.

33. My female care-giver often acts as if she doesn't care about me.

34. My female care-giver enjoys spending time with me.

35. My female care-giver expresses her warmth and affection for me. 
36. My female care-giver is easy for me to talk to.

37. I am tense and uneasy when my female care-giver and I are together.

38. I feel that my female care-giver finds fault with me more often than I deserve.

39. My female care-giver takes an active interest in my affairs.

40. I feel very close to my female care-giver.

41. My female care-giver does not understand me.

42. My female care-giver believes in me.

43. I don't feel that my female care-giver enjoys being with me.

44. My female care-giver doesn't really know what kind of person I am.

45. My female care-giver is a warm and caring individual.

46. My female care-giver does not feel that I am important and interesting.

47. My female care-giver is very interested in those things that concern me.

48. My female care-giver is often critical of me and nothing I do ever seems to please her.

49. My female care-giver seldom shows me affection.

50. My female care-giver consoles me and helps me when I am unhappy or in trouble.

51. My female care-giver is generally cold and removed when I am with her.

52. I receive a lot of affirmation from my female care-giver.

53. My female care-giver is very understanding and sympathetic.

54. My female care-giver does not really care much what happens to me.

55. Do you think this female care giver participates in at least 30 minutes of moderate cardiovascular exercise for five or more days each week? (circle one)

YES NO 


\section{Appendix B - Parental Authority Questionnaire (PAQ) and Parental Nurturance Scale (PNS) Pertaining to Male Care-Givers}

Instructions: For each of the following statements, use the 5-point scale (1 = strongly disagree, 5 = strongly agree) provided to indicate the number that best describes how that statement applies to you and your male care giver. Write the number on the line provided. Try to read and think about each statement as it applies to you and the relationship you currently have with your male care giver. There are no right or wrong answers, so don't spend a lot of time on any one item. We are looking for your overall impression regarding each statement. Be sure not to omit any items.

First, please indicate who you will be thinking about as you complete this questionnaire. Please think about a male who you consider to be the most important/primary care-giver in your life.
My Father
My Grandfather
My Uncle

My Step-Father

Other:(please write the relationship on the line provided)

\begin{tabular}{ccccc}
\hline 1 & 2 & 3 & 4 & 5 \\
Strongly & Disagree & Neither disagree & Agree & Strongly \\
Disagree & & nor agree & & Agree
\end{tabular}

1. While I was growing up my male care-giver felt that in a well-run home the children should have their way in the family as often as the care-givers do.

2. Even if his children didn't agree with him, my male care-giver felt that it was for our own good if we were forced to conform to what he thought was right.

3. Whenever my male care-giver told me to do something as I was growing up, he expected me to do it immediately without asking any questions.

4. As I was growing up, once family policy had been established, my male care-giver discussed the reasoning behind the policy with the children in the family.

5. My male care-giver has always encouraged verbal give-and-take whenever I have felt that family rules and restrictions were unreasonable.

6. My male care-giver has always felt that what children need is to be free to make up their own minds and to do what they want to do, even if this does not agree with what the care-givers might want.

7. As I was growing up my male care-giver did not allow me to question any decision he had made. 
8. As I was growing up my male care-giver directed the activities and decisions of the children in the family through reasoning and discipline.

9. My male care-giver has always felt that more force should be used by care-givers in order to get their children to behave the way they are supposed to.

10. As I was growing up my male care-giver did not feel that I needed to obey rules and regulations of behavior simply because someone in authority had established them.

11. As I was growing up I knew what my male care-giver expected of me in my family, but I also felt free to discuss those expectations with my male care-giver when I felt that they were unreasonable.

12. My male care-giver felt that wise care-givers should teach their children early just who is boss in the family.

13. As I was growing up, my male care-giver seldom gave me expectations and guidelines for my behavior.

14. Most of the time as I was growing up my male care-giver did what the children in the family wanted when making family decisions.

15. As the children in my family were growing up, my male care-giver consistently gave us direction and guidance in rational and objective ways.

16. As I was growing up my male care-giver would get very upset if I tried to disagree with him.

17. My male care-giver feels that most problems in society would be solved if caregivers would not restrict their children's activities, decisions, and desires as they are growing up.

18. As I was growing up my male care-giver let me know what behavior he expected of me, and if I didn't meet those expectations, he punished me.

19. As I was growing up my male care-giver allowed me to decide most things for myself without a lot of direction from him.

20. As I was growing up my male care-giver took the children's opinions into consideration when making family decisions, but he would not decide for something simply because the children wanted it.

21. My male care-giver did not view himself as responsible for directing and guiding my behavior as I was growing up. 
22. My male care-giver had clear standards of behavior for the children in our home as I was growing up, but he was willing to adjust those standards to the needs of each of the individual children in the family.

23. My male care-giver gave me direction for my behavior and activities as I was growing up and he expected me to follow his direction, but he was always willing to listen to my concerns and to discuss that direction with me.

24. As I was growing up my male care-giver allowed me to form my own point of view on family matters and he generally allowed me to decide for myself what I was going to do.

25. My male care-giver has always felt that most problems in society would be solved if we could get care-givers to strictly and forcibly deal with their children when they don't do what they are supposed to do as they are growing up.

26. As I was growing up my male care-giver often told me exactly what he wanted me to do and how he expected me to do it.

27. As I was growing up my male care-giver gave me clear direction for my behaviors and activities, but he was also understanding when I disagreed with him.

28. As I was growing up my male care-giver did not direct the behaviors, activities, and desires of the children in the family.

29. As I was growing up I knew what my male care-giver expected of me in the family and he insisted that I conform to those expectations simply out of respect for his authority.

30. As I was growing up, if my male care-giver made a decision in the family that hurt me, he was willing to discuss that decision with me and to admit it if he had made a mistake.

31. My male care-giver seldom says nice things about me.

32. I am an important person in my male care-giver's eyes.

33. My male care-giver often acts as if he doesn't care about me.

34. My male care-giver enjoys spending time with me.

35. My male care-giver expresses his warmth and affection for me.

36. My male care-giver is easy for me to talk to.

37. I am tense and uneasy when my male care-giver and I are together. 
38. I feel that my male care-giver finds fault with me more often than I deserve.

39. My male care-giver takes an active interest in my affairs.

40. I feel very close to my male care-giver.

41. My male care-giver does not understand me.

42. My male care-giver believes in me.

43. I don't feel that my male care-giver enjoys being with me.

44. My male care-giver doesn't really know what kind of person I am.

45. My male care-giver is a warm and caring individual.

46. My male care-giver does not feel that I am important and interesting.

47. My male care-giver is very interested in those things that concern me.

48. My male care-giver is often critical of me and nothing I do ever seems to please him.

49. My male care-giver seldom shows me affection.

50. My male care-giver consoles me and helps me when I am unhappy or in trouble.

51. My male care-giver is generally cold and removed when I am with him.

52. I receive a lot of affirmation from my male care-giver.

53. My male care-giver is very understanding and sympathetic.

54. My male care-giver does not really care much what happens to me.

55. Do you think this male care giver participates in at least 30 minutes of moderate cardiovascular exercise for five or more days each week? (circle one)

YES

NO 


\section{Appendix C - Godin's Leisure Time Exercise Questionnaire}

\section{Circle the appropriate response:}

1. Are you currently participating in physical activity as part of a class at school?

YES NO

2. If yes, is this class required as part of the graduation requirements for your school?

YES NO

3. Are you currently participating in a physical education class (i.e., weight lifting; body conditioning) that is either highly suggested or required for you because of your participation in a sport program at school?

YES NO

4. Considering a typical 7-day period (a week), how many days on the average do you do the following kinds of exercise for at least 60 minutes? Write in each circle the appropriate number of days per week that you participate in exercise for at least 60 minutes.

\section{Days per Week}

a) Strenuous Exercise (Heart Beats Rapidly)

(i.e., running, jogging, hockey, football, soccer, basketball, cross country skiing, roller skating, vigorous swimming, vigorous long distance bicycling)

b) Moderate Exercise (Not exhausting)

(i.e., fast walking, baseball, tennis, easy

bicycling, volleyball, easy swimming, popular and folk dancing)

c) Mild Exercise (Minimal Effort)

(i.e., yoga, archery, fishing from river bank, bowling, golf, easy walking)
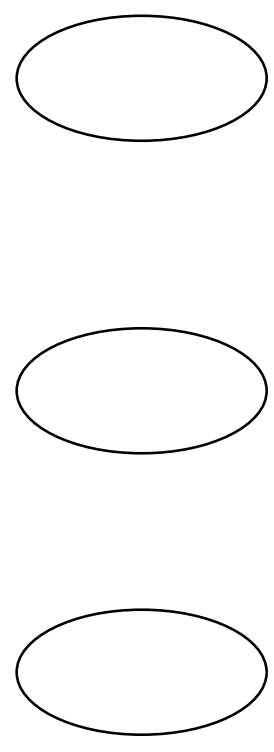
5. Considering a 7-day period (a week), during your leisure-time how often do you engage in any regular activity long enough to work up a sweat (heart beats rapidly)?

Often

Sometimes

Never/Rarely 


\section{Appendix D - Children's Attitudes Toward Physical Activity (CATPA) Inventory}

Instructions: This questionnaire is designed to find out how you feel about physical activity. Physical activities are games, sports, and dance such as tag, soccer, basketball, ballet and gymnastics.

At the top of each of the next few pages there is a box, and in the box there is an idea. Down below the box are five different pairs of words. You will be marking these words pairs to show how you feel about the idea. This is not a test, so there are no right or wrong answers. Read the idea in the box. Now go down to the first pair of words - Good-Bad. How do you feel about the idea in the box? If you think the idea is very good, you would put a " $\mathrm{X}$ " in the far left blank or, if you think the idea is very bad, you would put a " $X$ " in the far right blank. If you think the idea is pretty good but not super good you would put a " $X$ " in the second blank from the left or if you thought the idea was sort of bad but not really bad you would put a " $X$ " in the second blank from the right. If you think the idea is neither good nor bad (i.e., a neutral feeling) then put a " $\mathrm{X}$ " in the middle blank. If you do not understand the idea in the box put a " $\mathrm{X}$ " in the do not understand box on the middle of the page. Then go to the next page. If you understand the idea in the box but not the word pair, leave the word pair line blank and go on to the next word pair.

It is important for you to put your " $\mathrm{X}$ " right in the middle of the space-not on top of the dots. You should have five "X"s on every page to correspond with the 5 word pairs.

You may begin by reading the idea in the box at the top of the next page and fill in how you feel about all of the word pairs before you go on to the next page. Don't go back to a page after you have finished it; and don't try to remember how you answered the other pages. Think about each word pair by itself. As you go through the pages go fairly quickly; don't worry or think too long about any word pair. Mark the first thing that comes to your mind but don't be too careless. Remember, the idea the box at the top of each page is a new idea, so think only about that idea. 
How do you feel about the idea in the box?

\section{PHYSICAL ACTIVITY FOR SOCIAL GROWTH}

Taking part in physical activities which give you a chance to meet new people.

Always think about the idea in the box.

If you do not understand this idea, mark this box $\square$ and go on to the next page.

1.

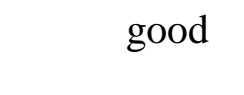

2.

$$
\text { of no use }
$$

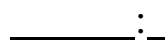

:

:

bad

3.

not pleasant

:

:

:__ useful

4.

nice

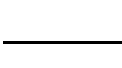

$:$

$:$

_

5.

happy

$:$

:

awful

5.

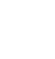

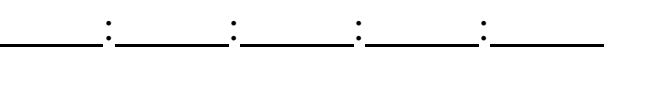

sad

The format of this questionnaire is the same for the other six dimensions of physical activity. The statements that appear in the box for the other six dimensions are listed below and are rated on the same five bi-polar adjective pairs.

PHYSICAL ACTIVITY TO CONTINUE SOCIAL RELATIONS: Taking part in physical activities which give you a chance to be with your friends.

PHYSICAL ACTIVITY FOR HEALTH AND FITNESS: Taking part in physical activities to make your health better and to get your body in better condition. 
PHYSICAL ACTIVITY AS A THRILL BUT INVOLVING SOME RISK: Taking part in physical activities that could be dangerous because you move very fast and must change direction quickly.

PHYSICAL ACTIVITY AS THE BEAUTY IN MOVEMENT: Taking part in physical activities which have beautiful and graceful movements.

PHYSICAL ACTIVITY FOR THE RELEASE OF TENSION: Taking part in physical activities to reduce stress or to get away from problems you might have.

PHYSICAL ACTIVITY AS LONG AND HARD TRAINING: Taking part in physical activities that have long and hard practices. To spend time in practice you need to give up other things you like to do. 


\section{Appendix E - Behavioral Regulation in Exercise Questionnaire-2 (BREQ-2)}

Age: years
White

Other:
Sex: male female (please circle)

African American Native American Asian

Ethnicity: (please circle) Hispanic or Latino

Not Hispanic or Latino

WHY DO YOU ENGAGE IN EXERCISE?

We are interested in the reasons underlying peoples' decisions to engage, or not engage in physical exercise. Using the scale below, please indicate to what extent each of the following items is true for you. Please note that there are no right or wrong answers and no trick questions. We simply want to know how you personally feel about exercise. Your responses will be held in confidence and only used for our research purposes.

1) I exercise because other people

Not true

Sometimes

for me say I should.

true for me

Very True

for me

2) I feel guilty when I don't exercise.

0

1

2

3

4

3) I value the benefits of exercise.

0

2

3

4

4) I exercise because its fun.

\section{0}

1

\section{2}

34

5) I don't see why I should have to exercise.

6) I take part in exercise because my friends/family/partner say I should.
7) I feel ashamed when I miss an exercise session.

8) It's important to me to exercise regularly.

9) I can't see why I should bother exercising.

10) I enjoy my exercise sessions.

11) I exercise because others will not be

0 pleased with me if I don't. 


$\begin{array}{ccc}\begin{array}{c}\text { Not true } \\ \text { for me }\end{array} & \begin{array}{c}\text { Sometimes } \\ \text { true for me }\end{array} & \text { Very True } \\ & \text { for me }\end{array}$

12) I don't see the point in exercising

13) I feel like a failure when I haven't exercised in awhile.

14) I think it is important to make the

$0 \quad 1$
effort to exercise regularly.

15) I find exercise a pleasurable activity.

$0 \quad 1$

2

3

4

$0 \quad 1$

2

3

4

16) I feel under pressure from my

$0 \quad 1$
friends/family to exercise.

17) I get restless if I don't exercise regularly.

18) I get pleasure and satisfaction from

$0 \quad 1$

2

3

4 participating in exercise.

19) I think exercise is a waste of time.

0

0

1

2

3

4 


\title{
Appendix F - Informed Consent
}

\author{
KANSAS STATE UNIVERSITY \\ Informed Consent
}

PROJECT TITLE: Family Dynamics and Health Attitudes (IRB \#5710)

APPROVAL DATE OF PROJECT: 2-7-2011

EXPIRATION DATE OF PROJECT: 2-7-2012

PRINCIPAL INVESTIGATOR: Brandonn S. Harris, PhD., Assistant Professor

CO-INVESTIGATOR(S): Rachel Y. Witham, B.S., Master's Candidate in School Counseling

CONTACT NAME AND PHONE FOR ANY PROBLEMS/QUESTIONS:

- Brandonn Harris, Assistant Professor, Department of Special Education, Counseling, and Student Affairs, 329 Bluemont Hall, Kansas State University, Manhattan, KS 66506, (785) 532- 5784

\section{IRB CHAIR CONTACT/PHONE INFORMATION:}

- Rick Scheidt, Chair, Committee on Research Involving Human Subjects, 203 Fairchild Hall, Kansas State University, Manhattan, KS 66506, (785) 532-3224.

- Jerry Jaax, Associate Vice President for Research Compliance and University Veterinarian, 203 Fairchild Hall, Kansas State University, Manhattan, KS 66506, (785) 532-3224.

SPONSOR OF PROJECT: Not-applicable

PURPOSE OF THE RESEARCH: The purpose of this research study is to explore adolescents' views of their family dynamics and how these dynamics are related to adolescents' attitudes regarding their health and health-related behaviors.

PROCEDURES OR METHODS TO BE USED: The participants in this study will be asked to complete a total of five questionnaires that relate to family dynamics and health-related behaviors, motivation, and attitude. Participants will not be video taped or audio recorded during the study.

LENGTH OF STUDY: Approximately 30 minutes

RISKS OR DISCOMFORTS ANTICIPATED: There are no known risks anticipated from participation in this research study.

BENEFITS ANTICIPATED: This study is expected to add to the research on the topic of physical activity behaviors in children and adolescents. By exploring variables related to child 
and adolescent physical activity participation, researchers and professionals will learn how to foster and facilitate these variables to increase physical activity participation and thus decrease the incidence of childhood obesity.

EXTENT OF CONFIDENTIALITY: Participants will not be asked to provide their names or any other identifying information on the measures beside general demographic characteristics (e.g., gender, age, and ethnicity). Results will be analyzed on a group basis and individual scores will not be examined.

\section{TERMS OF PARTICIPATION:}

I understand this project is research, and that my participation is completely voluntary. I also understand that if I decide to participate in this study, I may withdraw my consent at any time, and stop participating at any time without explanation, penalty, or loss of benefits, or academic standing to which I may otherwise be entitled.

I verify that my signature below indicates that I have read and understand this consent form, and willingly agree to participate in this study under the terms described, and that my signature acknowledges that $I$ have received a signed and dated copy of this consent form.

PARENTAL APPROVAL FOR MINORS: Parental signature required for any participant younger than 18 years of age.

I give my son/daughter permission to participate in the research study as outlined above.

Parent Name:

Parent/Guardian Signature:

Date:

Participant Name:

Participant Signature:

Date:

Witness to Signature:

Date: (project staff)

\section{ADDITIONAL INFORMATION (for the PARENT/GUARDIAN to complete):}

1. Do you participate in moderate cardiovascular exercise for at least 30 minutes on five or more days out of the week? (circle one)

YES NO 
2. Are you the female or male caregiver for your child? (check one)

$\square$ Female Care Giver $\quad \square$ Male Care Giver 